\title{
ZONEAMENTO DE SUSCEPTIBILIDADE A ESCORREGAMENTOS EM ENCOSTAS APLICADO À BACIA DE DRENAGEM URBANA DO CÓRREGO DO INDEPENDÊNCIA - JUIZ DE FORA (MG)
}

\author{
Ricardo Tavares Zaidan \\ Prof. Adjunto do Dep. Geociências-ICH-UFJF - Rua José Lourenço Kelmer, s/n - Campus Universitário - Bairro São \\ Pedro - Cep 36036-330 - Juiz de Fora - MG - Tel.:(32)2102-3121 - e-mail: ricardo.zaidan@ufjf.edu.br \\ Nelson Ferreira Fernandes \\ Prof. Associado do Dep. Geografia-IG-CCMN-UFRJ - Ilha do Fundão - Cep 21941 - Rio de Janeiro - RJ - \\ e-mail: nelsonff@uol.com.br
}

\begin{abstract}
Resumo
O desenvolvimento de metodologias para a previsão de ocorrência de escorregamentos vem assumindo importância crescente na literatura geomorfológica e geotécnica. Dentre as metodologias de previsão destes eventos, tem se destacado a utilização de modelos matemáticos, principalmente os modelos determinísticos que são baseados em processos físicos naturais e que levam em consideração os fatores topográficos no processo de modelagem e previsão da susceptibilidade dessas áreas com o auxílio de softwares de Geoprocessamento. Desta forma, este trabalho, que faz parte de uma tese de doutoramento, buscou contribuir através da aplicação de uma metodologia para a determinação de áreas susceptíveis a escorregamentos na região da bacia de drenagem urbana do Córrego Independência na escala 1:2.000, localizada no Município de Juiz de Fora - MG, através da utilização de um modelo determinístico denominado, Modelo SHALSTAB. Os resultados apresentados neste texto referem-se a um zoneamento gerado a partir do SHALSTAB, apontando as áreas de maior a menor susceptibilidade a movimentos de massa, seguido de sua análise, levando em relação os bairros e localidades situados na bacia do córrego Independência. Acredita-se desta forma que tal abordagem possa contribuir para o aprimoramento de metodologias que possam servir como subsídio para a definição de políticas que auxiliem o uso e ocupação de áreas com morfologia de encostas que ofereçam algum tipo de risco à população ou a algum empreendimento, não só nesse município.
\end{abstract}

Palavras-chave: Geomorfologia, Movimentos de Massa, Modelagem Matemática.

\begin{abstract}
The development of methodologies aimed to predict the occurrence of landslides, has been gaining importance in the geomorphologicial and the geotechnical literature. Among these methodologies, deterministic mathematical models, which are based on natural physical processes and that take into consideration the topographic factors in modeling and in predicting the unstable sites areas, have stood out. Therefore, the objective of this study is to contribute towards the development of a methodology to determine the areas at immediate occurrence and those that are potentially at susceptibility of occurrence of landslides. This research was carried out in an urban drainage basin ("Córrego Independência"), located in the city of Juiz de Fora - MG, at a 1:2.000 scale. Landslide susceptibility was predicted by the usage of a deterministic mathematical model (SHALSTAB). The results suggested many different areas considered with potential at susceptibility of occurrence of landslides. It is believed that such approach may contribute to the development of methodologies that may be useful to define policies of hillside urban areas, and that it may also contribute by giving support to the process of modernization of the City's Construction and Maintenance Code aiming at reducing the existing risks and avoiding the appearance of new risk areas.
\end{abstract}

Keywords: Geomorphology, Move Mass, Mathematical Models. 


\section{Introdução}

O Brasil, por sua grande extensão e diversidade de condições climáticas, está sujeito aos desastres naturais ou induzidos pela ação antrópica, principalmente aqueles associados às porções susceptíveis do seu relevo (AMARAL, 1996; FERNANDES e AMARAL, 1996).

Neste contexto destacam-se os movimentos de massa nas encostas, não somente em regiões naturais, mas também nos grandes adensamentos humanos das grandes e médias cidades desde a região nordeste até o sul do país (GUIDICINI e NIEBLE, 1984; AUGUSTO FILHO e VIRGILI, 2004). De acordo com dados da defesa civil da ONU, na última década do século passado, os movimentos de massa já chegaram a ocupar o terceiro lugar no ranking de vítimas fatais e destruição de edificações, perdendo apenas para os terremotos e inundações no mundo inteiro (FERNANDES e AMARAL, 1996).

O desenvolvimento de metodologias para a previsão de ocorrência dos escorregamentos vêm assumindo importância crescente na literatura geomorfológica e geotécnica. No entanto, há diferentes concepções do problema e diversas formas de investigação. Grande parte das metodologias propostas, por exemplo, visa à definição de áreas críticas a escorregamentos, ou seja, áreas com maior susceptibilidade de ocorrência do processo (por exemplo: GUZZETTI et al., 1999; GARCIA e ZÊEERE, 2004), e outros a probabilidade de ocorrência (por exemplo: XAVIER-DA-SILVA, 2001; LEE et al., 2004). Seguindo uma abordagem diferente, outros estudos, por sua vez, buscam caracterizar o risco envolvido, englobando tanto a possibilidade de ocorrência do processo quanto os danos decorrentes (por exemplo: AUGUSTO FILHO e WOLLE, 1996; CRUDEN, 1997; SOUZA et al., 2001; AMARAL e FURTADO, 2004). Dentre as metodologias de previsão destes eventos, tem se destacado a utilização de modelos matemáticos, principalmente os modelos determinísticos que são baseados em processos físicos naturais e que levam em consideração os fatores topográficos no processo de modelagem e previsão da susceptibilidade dessas áreas (FERNANDES et al., 2001).

Dentre os modelos matemáticos determinísticos podemos destacar o SHALSTAB, que tem sido utilizado com sucesso em diversas regiões da costa oeste dos EUA (como mencionado por MONTGOMERY, 1994; DIETRICH e MONTGOMERY, 1998), e mais recentemente utilizado em países como Itália, Argentina e Nova Zelândia, apresentando também resultados satisfatórios (RAFAELLI et al., 2001; CLAESSENS et al., 2005).

No Brasil, já foi utilizado no Estado do Rio de Janeiro, nas proximidades do Parque Nacional da Tijuca (GUIMARÃES, 2000; FERNANDES et al., 2001; GUIMARÃES et al., 2002; FERNANDES et al., 2004) e em Minas Gerais, na determinação de susceptibilidade a escorregamentos nas margens da rodovia $\mathrm{Br} 356$ no município de Ouro Preto (REDIVO et al., 2004) e para zoneamentos na região do Quadrilátero Ferrífero (RAMOS et al., 2002), mas ainda não se tem registros de sua utilização em áreas urbanas.

Em Juiz de Fora destacam-se algumas áreas por serem bacias de drenagem com ocupação urbana, que já tem registrado um número significante de ocorrências de escorregamentos, como é o caso da Bacia do Córrego Independência, próxima ao campus da UFJF - Universidade Federal de Juiz de Fora.

Desta forma, buscou-se com este trabalho contribuir através do desenvolvimento de uma metodologia para a determinação de áreas susceptíveis a escorregamentos no Município de Juiz de Fora, aplicada a uma bacia de drenagem urbana, através da utilização de um modelo determinístico o Modelo SHALSTAB (DIETRICH e MONTGOMERY, 1998). Acredita-se que tal abordagem venha contribuir com o desenvolvimento de metodologias que possam servir como subsídio para a criação de zoneamentos de riscos de escorregamentos e a definição de políticas de ocupação das encostas em áreas urbanas, de forma a apoiar o processo de modernização do Código de Obras Municipal e implantação de Planos de Ações Preventivas.

Desta forma, os objetivos específicos deste trabalho foram:

- Classificação e descrição do Uso e Ocupação na Bacia do Córrego Independência na escala 1:2.000;

- Classificação, validação do modelo e análise da distribuição espacial das Áreas Susceptíveis a Escorregamentos na Bacia do Córrego Independência na escala de 1:2.000;

- Zoneamento e análise da distribuição espacial das classes de Susceptibilidade a Escorregamentos Aplicado na Bacia do Córrego Independência;

\section{Embasamento Teórico}

\section{Movimentos de Massa: Teoria e Previsão}

\section{Aspectos Geomorfológicos}

Dentre os processos causadores de catástrofes em áreas urbanas podemos destacar os movimentos gravitacionais de massa, inseridos no âmbito da geomorfologia, podendo ser definida, de forma simplificada, como a ciência que estuda as formas do relevo do nosso planeta, preocupando-se não somente com as formas regionais, como também, com escalas maiores, como bacias hidrográficas e encostas (SMALL, 1978; PARSONS, 1988; SELBY, 1993).

\section{Movimentos de Massa}

As encostas compõem grande parte da superfície terrestre, sendo parte integrante do relevo, onde ocorrem pro- 
cessos que atuam constantemente em sua dinâmica (SMALL, 1978; CHORLEY e BECKINSALE, 1984). O estudo destes processos ajuda na compreensão desta dinâmica, destacando-se os movimentos de massa, que são fenômenos erosivos de larga envergadura que ocorrem no regolito, podendo ser provocados por diversos fatores (SELBY, 1993), e especialmente no Brasil, as chuvas possuem grande significância na deflagração dos mesmos (GUIDICINI e NIEBLE, 1984). Fernandes e Amaral (1996) atestam também, que estes são contínuos, de dinâmica externa, e que modelam a paisagem da superfície da terra, e ainda, a ação antrópica também pode acelerar sua deflagração.

De acordo com GUIDICINI e NIEBLE (1984), popularmente o termo deslizamento tem sido utilizado para designar qualquer evento gravitacional ou mesmo movimentos de massa ocorridos nas encostas brasileiras. Contudo, temos que nos atentar para o uso correto da nomenclatura. Sendo assim, os deslizamentos podem ser definidos pelo movimento gravitacional e descendente, para fora da encosta, do material desagregado sem a ajuda da água corrente como um agente de transporte (CROZIER, 1986; FERNANDES et al., 2001;
FERNANDES et al., 2004; VIEIRA e FERNANDES, 2004; ARAUJO et al., 2005).

Vários foram os autores que descreveram e classificaram os movimentos de massa (por ex. SHARPE, 1938; FREIRE, 1965; CARSON e KIRKBY, 1972; SCHEIDEGGER, 1975; TRICART, 1977; SMALL, 1978; VARNES, 1978; CLARK e SMALL, 1982; BRUNSDEN e PRIOR, 1984; CHORLEY e BECKINSALE, 1984; ABRAHAMS, 1986; FRANCIS, 1987; HUTCHINSON, 1988; PARSONS, 1988; SASSA, 1989; IPT, 1991; SELBY, 1993; MORGAN, 1995; KELLER, 1996; AHNERT, 1998; PRESS e SIEVER, 2000; CHRISTOFOLETTI, 2002), sendo que a maioria das classificações possui aplicabilidade regional, influenciadas pelo ambiente em que o autor que a elaborou se encontrava (GUIDICINI e NIEBLE, 1984). Em geral, os movimentos de massa podem ser classificados de acordo com o tipo do material, a velocidade e o mecanismo do movimento, o modo de deformação, a geometria da massa movimentada e o conteúdo de água (SELBY, 1993; FERNANDES e AMARAL, 1996).

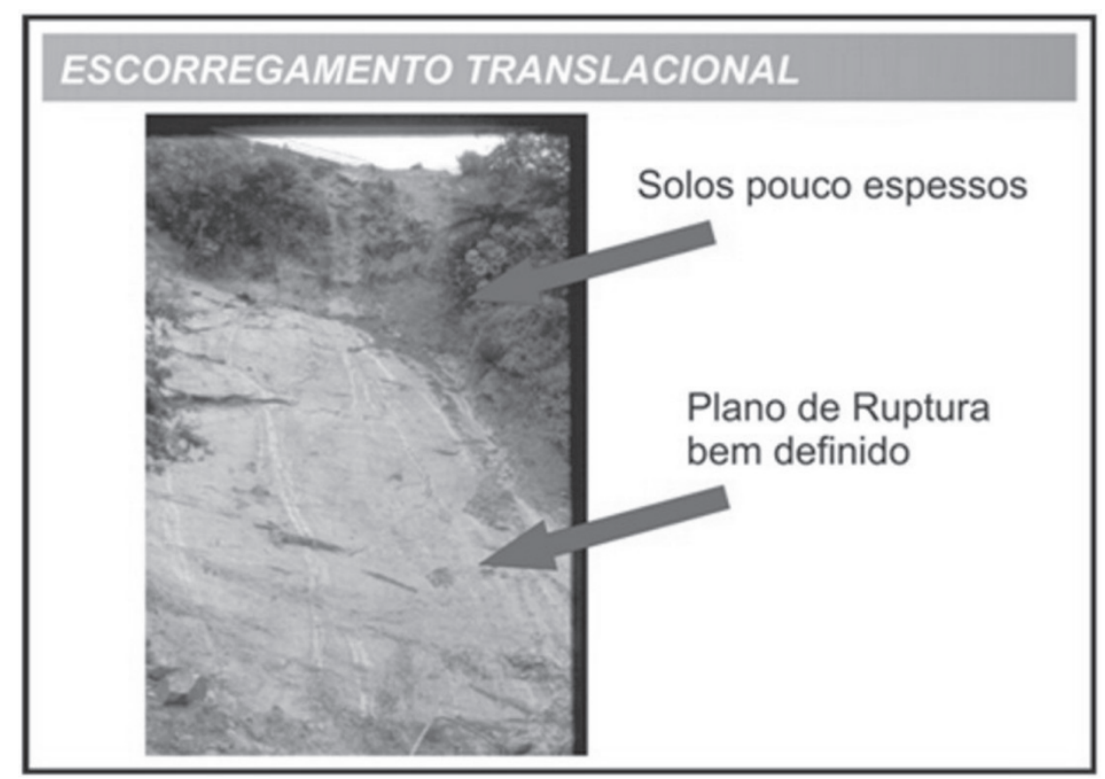

Figura 1 - Representação de um Escorregamento translacional onde ficam bem definidos o plano de ruptura sob solos pouco espessos Encosta em frente ao Posto do Garrafão BR-116 na Serra de Teresópolis, Prof. Nelson F. Fernandes, 1982. 
Dentre as classificações existentes, uma das mais utilizados internacionalmente até os dias de hoje, é a produzida por Varnes (1978). Já no Brasil, destaca-se o esquema proposto por Guidicini e Nieble (1984), que de forma simplificada, divide os movimentos de massa em escoamentos (englobando rastejos e corridas) escorregamentos (translacionais e rotacionais), subsidências e movimentos complexos (FERNANDES e AMARAL, 1996; FERNANDES et al., 2001; FERNANDES et al., 2004).

Neste contexto, Amaral e Feijó (AMARAL, 1997; AMARAL e FEIJÓ, 2004) mostraram que os escorregamentos rasos de solo, geralmente sob forma de movimentos translacionais, foram os mais importantes para a cidade do Rio de Janeiro nas últimas décadas, chegando a mais de $80 \%$ das ocorrências. Além disso, outros estudos nos levam a crer que tal comportamento não se limita ao Rio de Janeiro, sendo característico de todo o escarpamento da Serra do Mar (WOLLE e CARVALHO, 1989; LACERDA, 1997) e de áreas com características ambientais semelhantes, dentre as quais podemos mencionar as encostas da Serra da Mantiqueira, onde se localiza boa parte do município de Juiz de Fora. Apesar das ocorrências estarem muitas vezes ligadas à presença humana, os movimentos de massa da região assemelham-se com os escorregamentos do tipo translacional, sendo em alguns casos, seguidos de corridas, quando o material chega a atingir a calha do curso de água local.

Os Escorregamentos (landslides) são movimentos gravitacionais rápidos de curta duração, com volume e superfície de ruptura bem definidos, onde o material desprendido é jogado para fora da encosta, tendo como resultado, geralmente feições longas, como cicatrizes, podendo assumir geometria rotacional ou translacional. Os escorregamentos rotacionais (slumps) são escorregamentos com superfície de ruptura côncava, característicos de encostas em geral pouco fraturadas, com formações superficiais uniformes, solos espessos, como por exemplo, os originados de rochas argilosas como os argilitos e folhelhos. Já os escorregamentos translacionais (translacional landslide) são movimentos com plano de ruptura rasos bem definidos, que seguem muitas vezes paralelos à superfície da encosta. Tais planos podem ser formados por antigas estruturas geológicas, geomorfológicas ou pedológicas, podendo ser compostos por rochas, solos residuais, talus, colúvio, detritos ou a mistura dos mesmos (GUIDICINI e NIEBLE, 1984; FERNANDES e AMARAL, 1996) (Figura 1).

Corridas são escoamentos rápidos de caráter essencialmente hidrodinâmico, devido à presença de excesso de água em superfícies pouco coesas, propensas à perda de resistência, com materiais detríticos que agem como um fluido e que ajustam ao modelado do relevo através dos canais de drenagem. Podem ser de terra, areia e silte, de lama, fragmentos de rocha e vegetação, sendo que, a grande maioria das corridas associa-se a momentos de precipitações pluviais abundantes (GUIDICINI e NIEBLE, 1984; FERNANDES e AMARAL, 1996; PRESS e SIEVER, 2000).

\section{Metodologias de Previsão}

Uma das maneiras de se prever os movimentos de massa é através da utilização dos modelos que podem representar, simular, prever a susceptibilidade e até mesmo o risco desses processos sob a população.

Os modelos são estruturas simplificadas da realidade que apresentam feições ou relações significativas. Constituem aproximações altamente subjetivas por não incluírem todas as variáveis associadas, resultado natural devido à tendência do homem em simplificar a complexidade do mundo ao seu redor (CHRISTOFOLLETI, 1999).

Temos como uma das principais funções dos modelos a criação de respostas imediatas para tomada de decisões, na simulação e previsão de possíveis cenários de mudanças ambientais, na ligação entre mensurações de processos atuais com a evolução das formas e na sua aplicabilidade em todas as escalas (FERNANDES, 1996; CHRISTOFOLLETI, 1999).

O uso de modelos sempre foi muito difundido no campo das Geociências, porém, tornou-se mais explícito a partir da década de 60 com o lançamento das obras "An Introduction to Statistical Models in Geology" (KRUMBEIN e GRAYBILL, 1965) e a coletânea de ensaios "Models in Geography" (CHORLEY e HAGGETT, 1967) (ambos mencionados por CHRISTOFOLLETI, 1999), traduzida para o português em três obras: Modelos Integrados em Geografia, Modelos Sócio-Econômicos em Geografia e Modelos Físicos e de Informação em Geografia, ganhando um grande avanço através da teoria probabilística e da adoção de modelos matemáticos na década de 1970 , reforçada pelo uso dos computadores a partir de 1980, sendo nos dias de hoje, uma das mais importantes linhas de pesquisa geomorfológica (CHRISTOFOLLETI, 1999).

Uma variedade de metodologias tem sido desenvolvidas para a análise de predição dos movimentos de massa, sendo alvo de inúmeras análises e discussões (FERNANDES et al., 2001; FERNANDES et al., 2004), porém, a utilização de modelos determinísticos em bases físicas ou em processos vêm crescendo por permitirem, entre outras coisas, que hipóteses bem específicas possam ser testadas, tanto na escala de encosta quanto na bacia de drenagem inteira (FERNANDES e AMARAL, 1996). Este tipo de modelo não tem interferência direta do operador no resultado, ou seja, a subjetividade está relacionada somente à escolha dos parâmetros a serem utilizados no modelo e não no seu resultado final, tornando a decisão baseada em processos seguindo as leis da natureza, não delegando às técnicas dos SIGs o poder de decisão (GOMES, 2002; GOMES et al., 2004; GOMES et al., 2005). 
SHALSTAB: modelagem de susceptibilidade a escorregamentos translacionais rasos em encostas

O SHALSTAB é um modelo matemático determinístico distribuído que trabalha sobre uma estrutura matricial, podendo ser transiente ou não, ou seja, possibilita a adoção de valores diferenciados para suas variáveis ao longo da estrutura matricial, observando-se a não existência de qualquer tipo de aleatoriedade destes valores. Seu desenvolvimento se deu no início da década de 90 por Willian Dietrich, na Universidade da Califórnia em Berkeley (DIETRICH et al., 1992; DIETRICH, 1993; MONTGOMERY e DIETRICH, 1994), recebendo finalmente esta nomenclatura quando lançada uma versão mais amigável para ser utilizada em ambiente Windows através de uma extensão do software Arcview, a partir da versão 3 (DIETRICH e MONTGOMERY, 1998).

O SHALSTAB é utilizado para prever áreas susceptíveis à ocorrência de escorregamentos translacionais rasos onde esteja bem definido um plano de transição com forte diminuição do processo de infiltração, como transição solo rocha, não sendo tão eficaz para aplicações em áreas de solos espessos, áreas com baixa declividade, afloramentos de rochas, e áreas escarpadas (GUIMARÃES, 2000).

Este modelo tem sido utilizado com sucesso em diversas regiões da costa oeste dos EUA (como mencionado por MONTGOMERY, 1994; DIETRICH e MONTGOMERY, 1998) apresentando resultados com excelente precisão
(CASADEI et al., 2003), e também em países como Itália, Argentina e Nova Zelândia, onde tem sido utilizado com diversos tipos de resolução, testado e comparado com outros modelos de previsão (RAFAELLI et al., 2001; CLAESSENS et al., 2005).

No Brasil, foi introduzido através de estudos e testes em bacias do Estado do Rio de Janeiro, nas proximidades do Parque Nacional da Tijuca (GUIMARÃES, 2000; FERNANDES et al., 2001; GUIMARÃES et al., 2002; FERNANDES et al., 2004), e testada sua precisão em diversas escalas (GOMES, 2002; GOMES et al., 2004), sendo posteriormente estendida sua área de aplicação para Minas Gerais como na determinação de susceptibilidades a escorregamentos nas margens da rodovia $\mathrm{Br} 356$ no município de Ouro Preto (REDIVO et al., 2004) e para zoneamentos na região do Quadrilátero Ferrífero (RAMOS et al., 2002).

O modelo SHALSTAB é construído através da combinação dos modelos de estabilidade de encosta, baseado na teoria de Fator de Segurança (FS) (MORGENSTERN e SANGREY, 1978), e do modelo hidrológico, que define um padrão de saturação na topografia baseado na relação entre a área drenada (a), o seu fechamento ou exultório, através do comprimento do contorno ao longo de sua curva de nível (b) e o ângulo da encosta do terreno $(\theta)$, desenvolvido a partir da junção dos modelos criados por BEVEN e KIRKBY (1979) e O’Loughlin (1986) (Figura 2).

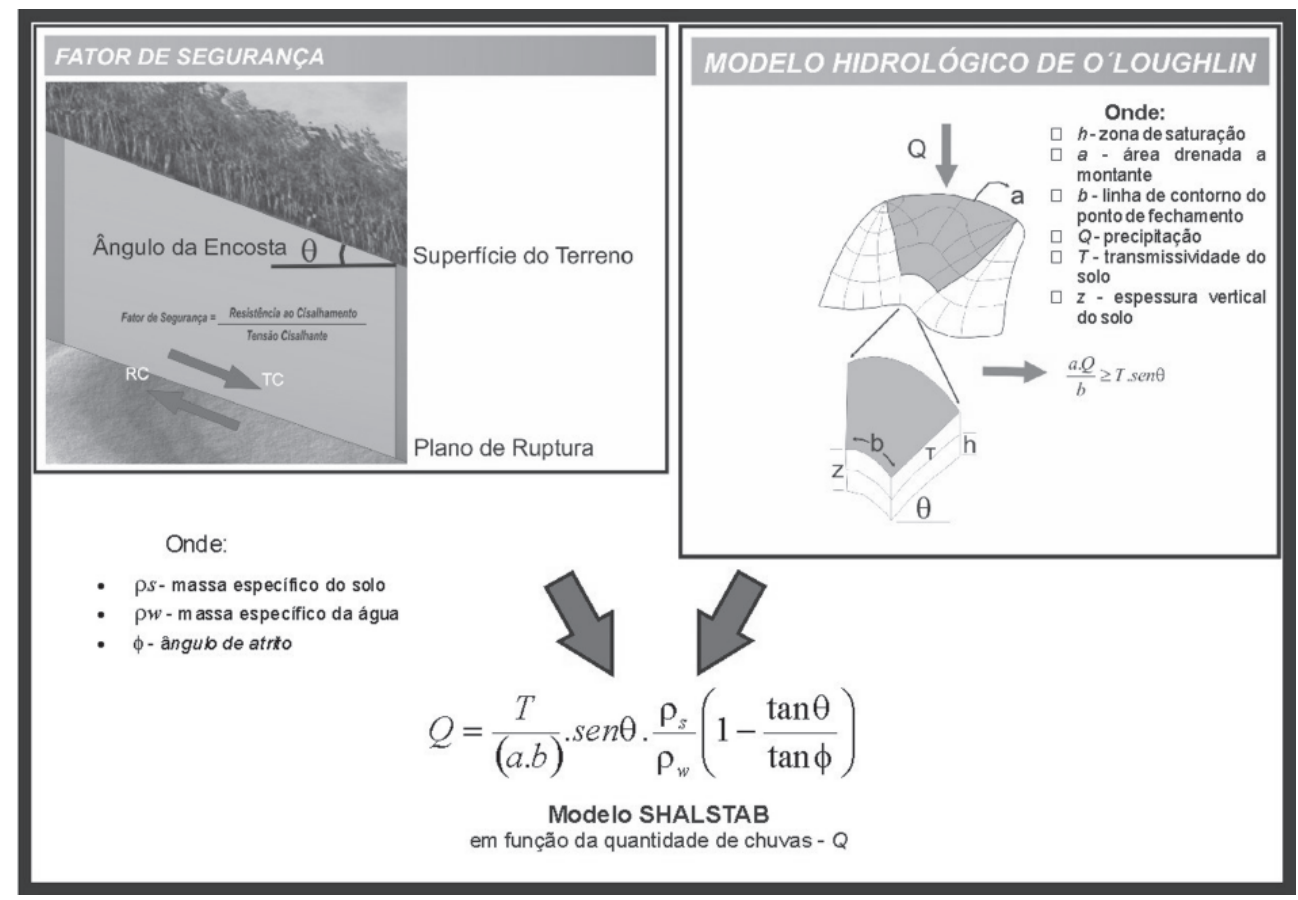

Figura 2 - Demonstrativo do Modelo SHALSTAB a partir dos modelos de estabilidade e hidrológico. 


\section{Área de Estudo}

A área de estudo é a bacia do Córrego Independência, sub-bacia do Rio Paraibuna, pertencente à bacia do rio Paraíba do Sul. A bacia do Córrego Independência está localizada dentro do perímetro urbano do Município de Juiz de Fora, pertencente à Região da Zona da Mata de Minas Gerais, Região Sudeste do Brasil. Localiza-se a aproximadamente 200Km da cidade do Rio de Janeiro e a $300 \mathrm{Km}$ da cidade de Belo Horizonte, através da rodovia $\mathrm{Br} 040$.

\section{Materiais e Métodos}

A escolha do município de Juiz de Fora se deu pelo fato de haver a existência de áreas de ocupação críticas com o registro de ocorrências de movimentos de massa caracterizados como escorregamentos translacionais rasos.

\section{A caracterização de Áreas Críticas no Município de Juiz de Fora}

Para a caracterização de áreas críticas no município, trabalhou-se na escala de 1:50.000, através de 6 cartas topográficas do IBGE na escala 1:50.000 que cobrem a área do Município de Juiz de Fora (IBGE, 1976a;b;c;d;e;f).

Realizou-se a análise da declividade do terreno com os limites das bacias hidrográficas da área Municipal para verificar onde se encontram as áreas de maiores declividades das bacias de drenagem com uso e ocupação urbana. Em seguida verificou-se, em campo, algumas dessas áreas mais próximas do centro da cidade onde a densidade demográfica é mais elevada, fazendo o registro fotográfico e análise da situação onde se detectou a presença de áreas críticas a ocorrência de movimentos de massa.

A escolha da Bacia do Córrego Independência seguiu critérios que definissem uma bacia essencialmente urbana, ou seja, que se encontrasse em mais de cinquenta por cento sob uso e ocupação urbana. O segundo critério foi o fato da bacia não estar totalmente ocupada, para que os resultados do zoneamento pudessem gerar algum efeito positivo para as futuras ocupações, caso os órgãos públicos responsáveis venham a levar em consideração este trabalho. O último critério foi a existência e a disponibilidade de material cartográfico para a geração dos mapas necessários ao desenvolvimento deste trabalho, visto que até mesmo nos dias de hoje encontra-se uma certa dificuldade na obtenção de produtos em escala de detalhe suficiente.

\section{Da Caracterização do Mapa de Uso e Ocupação da Bacia do Córrego Independência}

O primeiro procedimento constou da criação de uma base cartográfica digital contendo os mapas de altimetria, a cobertura aerofotográfica e o arruamento da bacia hidrográfica do Córrego Independência.

O mapa de altimetria foi criado a partir da edição das curvas de nível e a drenagem contidos na restituição aerofotogramétrica, escala 1:2000 de 1983, folhas R093A, R094A, R098A, R099A, R100A, R106A, R107A, R108A, R115A, R116A, R117A, R118A, R125A, cedidas pela prefeitura municipal em meio digital já vetorizadas (EMBRAFOTO, 1983). A cobertura aerofotográfica foi cedida pela prefeitura municipal através de um mosaico georreferenciado com a cobertura da área da Bacia do Córrego Independência com resolução de $40 \mathrm{~cm}$ o pixel (CESAMA/ PMJF, 2000). O mapa de arruamento foi cedido pela prefeitura municipal em meio digital já vetorizadas (PMJF, 1999;2004).

O segundo procedimento foi o processamento de alguns dos mapas contidos na base cartográfica para a geração do mapa de uso e ocupação, o modelo digital de elevação, a carta de declividades e a compartimentação geomorfológica da área municipal.

O mapa de uso e ocupação foi criado a partir da fotointerpretação da cobertura fotográfica e criação de três classes nominais distintas de uso e ocupação: as áreas de "Mata Urbana", as "Pastagens ou Loteamento não Edificados" e as "Áreas de Uso e Ocupação Urbana". Foram especificadas apenas três classes devido ao fato de ser necessário para o nosso trabalho apenas a distinção de área urbana e não urbana, não sendo necessária a distinção de tipos diferenciados de área urbana.

O modelo digital de elevação e a carta de declividades foram geradas com resolução de 1 metro o pixel, obedecendo os critérios de precisão cartográfica de 1:2.000, através do módulo de análise espacial do software Arcgis.

O mapa de ambientes geomorfológicos foi gerado a partir da análise das curvas de nível, da drenagem e do modelo de elevação sendo feita uma classificação nominal dos compartimentos de topo, encostas e fundos de vales.

\section{Da Previsão de Áreas Susceptíveis a Escorregamentos até o Zoneamento de Áreas Susceptíveis a Escorregamentos na Bacia do Córrego Independência}

Para a previsão de áreas susceptíveis a escorregamentos foram realizadas as etapas de geração do modelo de susceptibilidade, sua validação e a criação do zoneamento de susceptibilidade a escorregamentos.

Para a geração do modelo de susceptibilidade gerou-se um MDE - modelo digital de elevação raster - utilizou-se das curvas de nível e da drenagem, e através do módulo de análise espacial do Arcgis - Topo to Raster, pois segundo alguns autores tem sido considerado um dos métodos mais adequados para representação superficial com maior coerência com 
Errata: página 63 correta.

Zoneamento de susceptibilidade a escorregamentos em encostas aplicado à bacia de drenagem urbana do córrego do Independência Juiz de Fora (MG)

os processos hidrológicos (GUIMARÃES, 2000; RABACO, 2005). Em relação ao valor das variáveis necessárias ao SHALSTAB, utilizou-se das medidas já pré-estabelecidas pelo programa de ângulo de atrito interno do solo $\left(45^{\circ}\right)$ e massa específica do solo $\left(1800 \mathrm{~kg} / \mathrm{m}^{3}\right)$ do Modelo SHALSTAB para a geração do modelo de susceptibilidade a partir da razão quantidade precipitada pela transmissividade dos solos $(Q / T)$, sem considerar a coesão dos solos $(C)$.

Após a geração do modelo, respeitando as potencialidades e deficiências do mesmo, os resultados obtidos nas porções de topos e de vales, foram anulados por não serem considerados precisos. Desta forma, todas as análises a seguir foram realizadas dentro apenas dos compartimentos de encosta da área da Bacia do Córrego Independência.

Para a validação do modelo de susceptibilidades foram mapeadas as cicatrizes de possíveis movimentos de massa pretéritos através da análise do mapa com a cobertura aerofotográfica da bacia, e através da interpretação do mapa de susceptibilidade, foi conferido se realmente apareceram células com classificação de instabilidade dentro da área das cicatrizes.

Para a criação do zoneamento de susceptibilidade a escorregamentos foram analisadas e agrupadas as classes ordinais obtidas através do modelo SHALSTAB da seguinte forma: a união das classes Incondicionalmente Instável Saturado e não Saturado com a Estável e não Saturado originaram a classe "Áreas Estáveis; a união das classes Instável Saturado e não Saturado originaram a classe "Áreas de Média Instabilidade"; e a união das classes Incondicionalmente Instável Saturado e não Saturado originaram a classe "Áreas Instáveis".

\section{Resultados}

Os resultados apresentados são relativos à caracterização de áreas críticas em escala municipal (1:50.000) e do detalhamento (1:2.000), através da previsão de áreas susceptíveis a escorregamentos da bacia de drenagem urbana do Córrego Independência.

\section{A caracterização de Áreas Críticas no Município de Juiz de Fora}

A organização do espaço municipal se deu inicialmente através da distribuição histórica das sesmarias e da instalação de equipamentos que dessem suporte ao deslocamento das tropas imperiais, transporte de minérios preciosos e comerciantes.

Com as primeiras ocupações populacionais, a organização espacial configurou-se nas proximidades do Rio Paraibuna, principalmente ao longo do seu vale principal, caracterizado por feições de relevo mais favoráveis, com pouco desnível e baixas declividades. Com o aumento do número de habitantes, a paisagem urbana ganhou espaço através dos vales secundários das sub-bacias tributárias do Paraibuna, nos dias atuais, avançando aceleradamente pelas encostas íngremes onde se aloca grande parte da população. Tal fisionomia revelou em muitas situações, o aparecimento de áreas críticas e degradadas onde se caracterizam situações de risco atual (Figura 3).

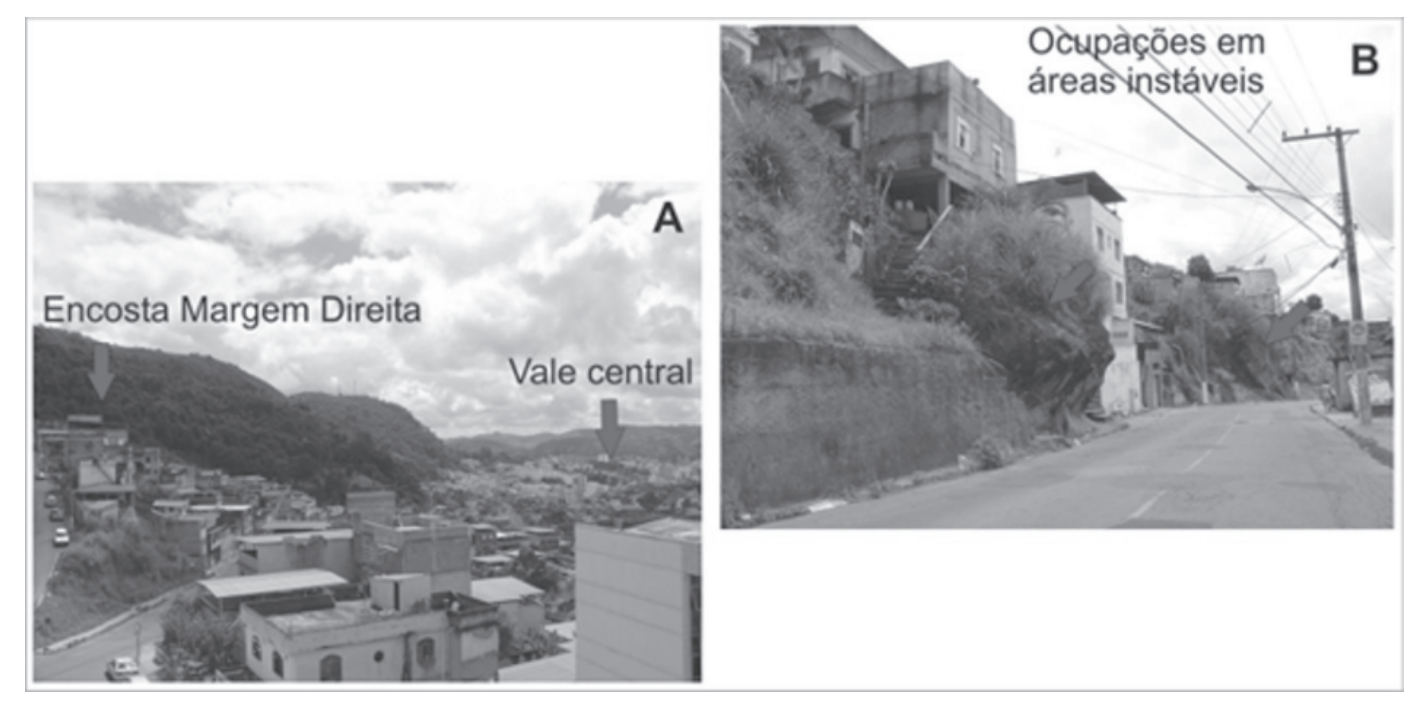

Figura 3 - A fotografia A mostra a área urbana no vale central e parte de sua extensão em direção às encostas da margem direita do Rio Paraibuna. A fotografia B mostra um detalhe da encosta apresentada na fotografia A, onde existem moradias instaladas sobre o terço inferior da encosta com a presença de depósitos de talos caracterizando instabilidade e formação de áreas críticas. 
A área onde se instalou a população do município de Juiz de Fora é bem caracterizada por um lineamento de sentido noroeste-sudeste que corta o perímetro urbano, acompanhando a calha principal do Rio Paraibuna, onde se encontra um grande vale, tendo em alguns trechos até $2 \mathrm{~km}$ de largura. $\mathrm{O}$ município também é cortado por dois grandes rios de expressão, o Rio Cágado e o Rio do Peixe, porém, somente o Rio Paraibuna passa pelo Perímetro Urbano, nossa área de estudo. Parte deste lineamento atribui-se a existência de um falhamento, bem identificado através do desnível entre as encostas do Morro do Cristo e o vale onde se encontra o centro da cidade. Tais características podem ser observadas através da fotografia A da figura 9, onde aparece um grande desnível entre a encosta da margem direita e o vale central onde passa o Rio Paraibuna. Perpendicularmente a este lineamento, encontramse vários outros que também cortam várias porções do perímetro urbano, inclusive o centro da cidade. Tal característica pode ser considerada como um dos fatores condicionantes na formação das sub-bacias das duas margens do Rio Paraibuna que se dispõem perpendicularmente a ele, seguindo a direção longitudinal aproximadamente Nordeste-Sudoeste em ambas as margens. Neste cenário de vales secundários em forma de anfiteatros, configuram-se encostas com percentual de declividade bem mais elevado que o vale central.
O Rio Paraibuna apresenta mais de 250 sub-bacias na área municipal, sendo 156 só no perímetro urbano. É neste contexto que destacam-se algumas destas bacias urbanas onde a ocupação se apresenta mais proeminente juntamente com características morfológicas do relevo que conferem maior susceptibilidade a ocorrência de processos como movimentos de massa que resultam em cenários críticos do ponto de vista geotécnico. Dentre estas bacias, destaca-se a bacia do Córrego Independência por apresentar tais características aliadas a uma grande densidade ocupacional, alem de já registrar junto a Defesa Civil de Juiz de Fora um número considerável de ocorrência de pequenos movimentos de massa.

\section{Uso e Ocupação e a Bacia do Córrego Independência}

A Bacia do Córrego Independência caracteriza-se como uma bacia essencialmente urbana e parte da sua área localiza-se na área classificada como centro comercial do município. Constata-se através da análise da cobertura aerofotográfica, que a maior parte de sua superfície já se encontra sob uso e ocupação essencialmente urbano, e sua paisagem demonstra total distinção entre o urbano e o não urbano, através das poucas áreas que ainda possuem cobertura verde (Figura 4).

\section{Cobertura Aerofotográfica da Bacia do Córrego Independência}

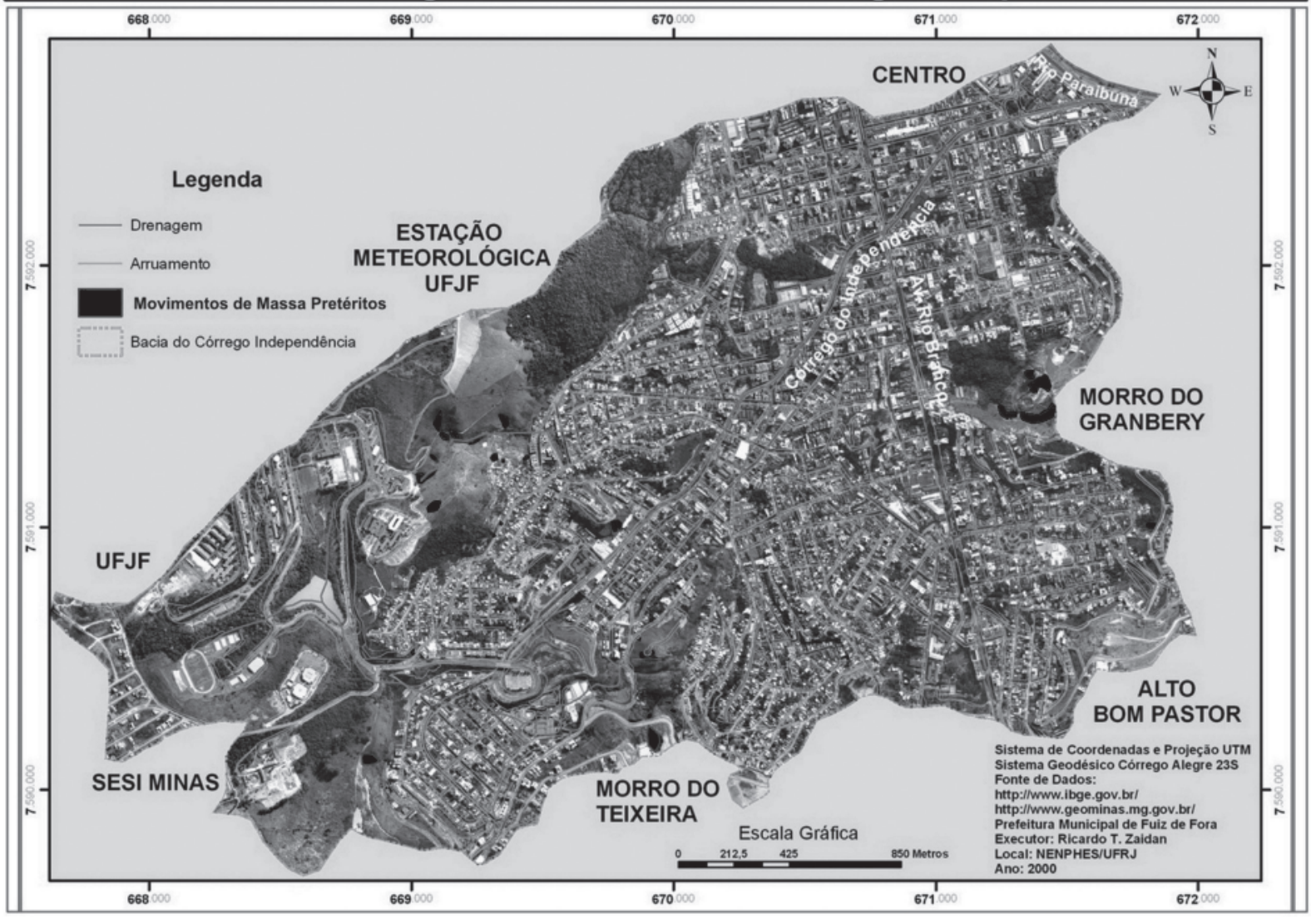

Figura 4 - Cobertura aerofotográfica da área da Bacia do Córrego Independência onde contrastamos ambientes urbanos dos não urbanos, como as pastagens e matas. 
Levando em consideração o interesse principal do nosso estudo, a detecção de áreas com susceptíveis a escorregamentos, ou seja, aqui identificadas por nós também como áreas críticas, definimos três classes distintas de uso e ocupação: as áreas de
"Mata Urbana", as "Pastagens ou Loteamento não Edificados" e as "Áreas de Uso e Ocupação Urbana". Tais classes estão representadas através do Mapa de "Uso e Ocupação da Bacia do Córrego Independência” (Figura 5).

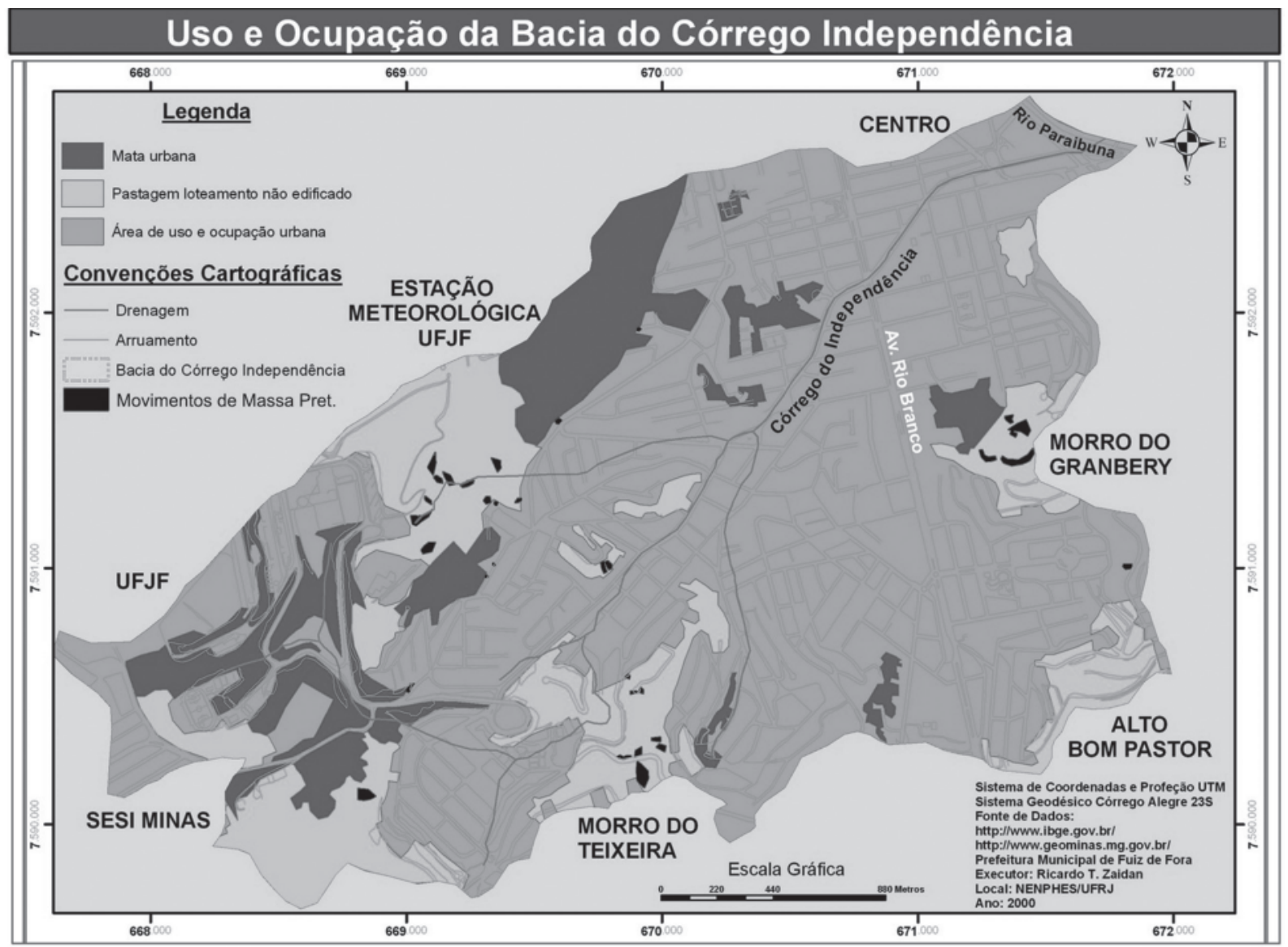

Figura 5 - Mapa representativo das classes de uso e ocupação do solo da área da Bacia do Córrego Independência.

A classe de Mata Urbana corresponde às áreas com vegetação arbórea ou arbórea arbustiva, equivalendo a 12,6\% da área total da Bacia do Córrego Independência (Gráfico 1).

As Matas Urbanas (Figura 6) são mais frequentes nas proximidades dos divisores de água da bacia hidrográfica, aparecendo também na área central em menor escala, correspondendo a antigas propriedades como instituições religiosas e públicas. Aparecem com maior frequência na porção noroeste até o sudoeste da bacia, que correspondem às escarpas do Morro do Cristo e à área da Universidade Federal de Juiz de Fora respectivamente. São típicas de feições de encostas de média a elevada declividade e também de alguns raros ambientes de topos ainda não loteados. Constata-se também, que em sua maioria, cobrem ambientes de maior dificuldade de ocupação, que nos dias de hoje, com o crescimento da população urbana, tem sofrido grande pressão de ocupação, principalmente por localizar-se nas proximidades do centro comercial da cidade.

Gráfico 1 - Representação do percentual (\%) da área das classes de uso e ocupação mapeados na Bacia do Córrego Independência (Figura 4).

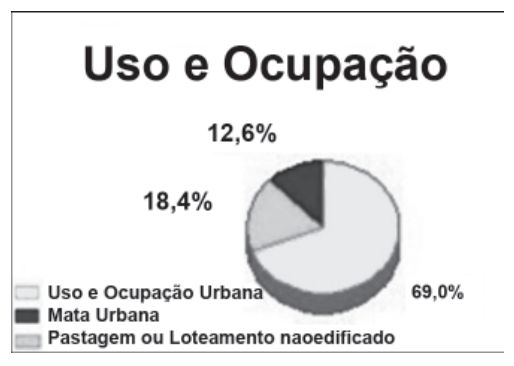




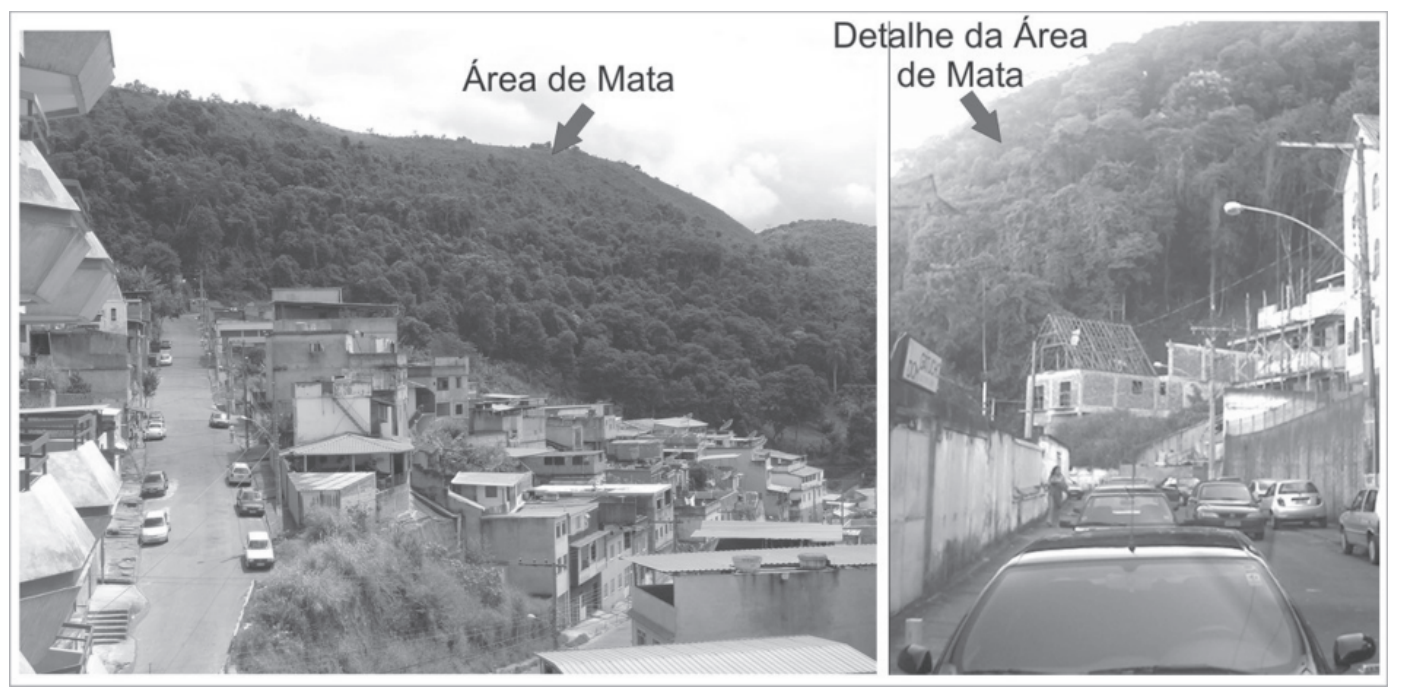

Figura 6 - Representação da área de mata onde a fotografia A nos mostra a cobertura típica de Mata Urbana e a fotografia B nos dá um detalhe da área de borda, onde avançam as edificações sobre a mata.

A classe Pastagem ou Loteamento não Edificado (Figura 7) corresponde às áreas que não são cobertas por matas e que ainda não possuem infra-estrutura de loteamento como arruamentos e edificações, correspondendo a $18,4 \%$ da área da Bacia do Córrego Independência (Gráfico 1). Estão localizadas nas regiões dos divisores de água da bacia e nas proximidades ou entorno de algumas matas. Aparecem também no centro, porém nas porções mais próximas das cabeceiras. Ocorrem em maior frequência nas porções de noroeste a sudoeste, principalmente na área correspondente a parte do campus da Universidade Federal de Juiz de Fora e suas vizinhanças. Caracterizam-se por ocuparem as porções mais elevadas da bacia, tanto ambientes de encostas, com declividades variadas, como topos de elevações e algumas poucas porções de vales mais elevados, distantes da região do vale central da bacia. Constata-se que esta classe caracteriza-se por sofrer pressão de ocupação constate por parte das populações vizinhas, registrando a ocorrência sistemática de queimadas, cortes de talude e ocupações muitas vezes por invasões.

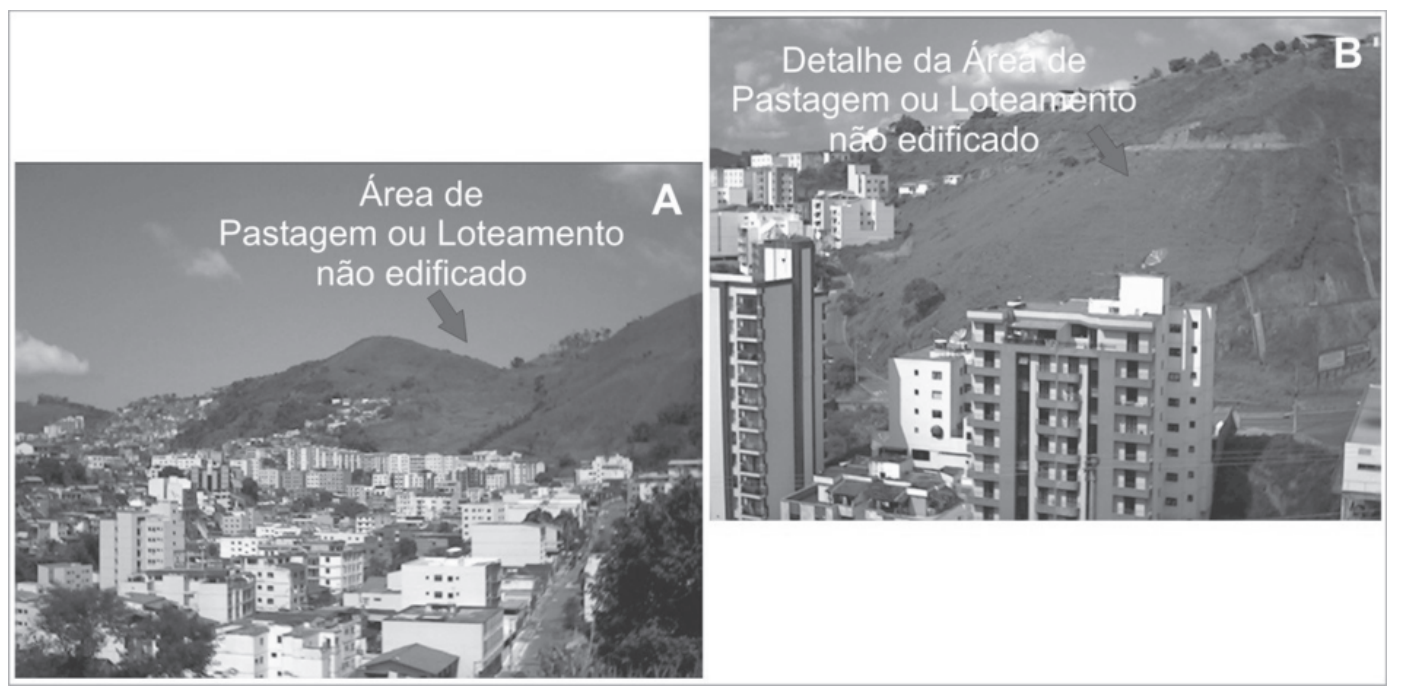

Figura 7 - A Fotografia A caracteriza a classe de Pastagem Loteamento não edificado e sua proximidade das áreas urbanas. A Fotografia B mostra um detalhe da área da Fotografia A, onde a paisagem de edificações avança através de cortes nas encostas de elevada declividade. 
A classe Áreas de Uso e Ocupação Urbana (Figura 8) caracteriza-se por uma paisagem de áreas urbanas ocupada por edificações de um ou vários pavimentos, e usos desde o residencial ao comercial, correspondendo a maior parte da área da Bacia do Córrego Independência, totalizando $69 \%$ da bacia (Gráfico 1). Estende-se por toda a porção central da bacia, desde o Rio Paraibuna passando pelas porções sudeste, sul e sudoeste, sendo essa última a de menor ocorrência. Sua mai- or ocorrência se dá no vale central, porém, nas bordas da Bacia do Córrego Independência já começam a expandir-se pelas encostas, ocupando as áreas de menor declividade. Nos atuais dias, exerce forte pressão e começa a invadir encostas mais íngremes, como as da porção sudoeste, alcançando altitudes mais elevadas nas proximidades das escarpas da região noroeste e nos platores da porção sudoeste, nos arredores da Universidade Federal de Juiz de Fora.

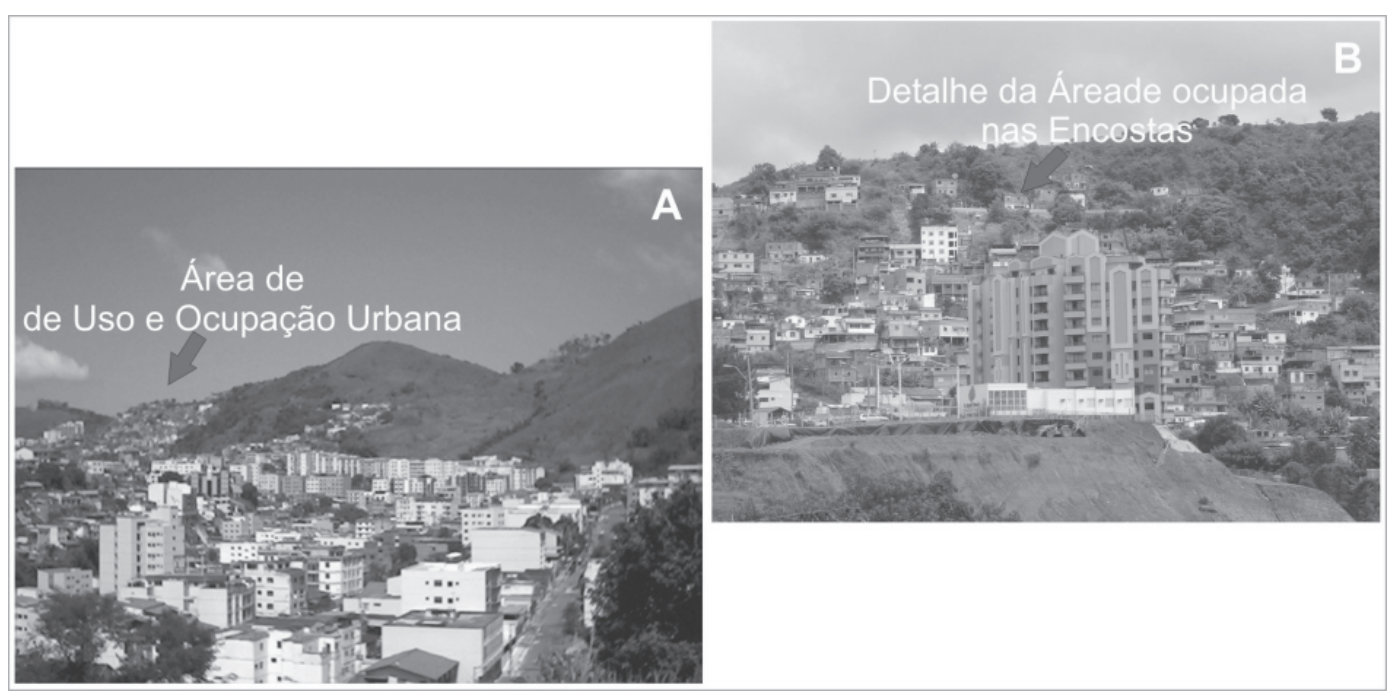

Figura 8 - A fotografia A mostra parte do vale central com ocupação urbana e suas extensões em direção às áreas com maior ângulo de encosta. A fotografia B detalha uma parte da encosta representada na fotografia A, onde a ocupação urbana ganha densidade em áreas de declividade inadequada para tal tipo de ocupação.

\section{Previsão de Áreas Susceptíveis a Escorregamentos na Bacia do Córrego Independência}

Este item aborda os resultados relativos ao Modelo de previsão de áreas susceptíveis a escorregamentos nas encostas da Bacia do Córrego Independência em duas etapas. A primeira etapa constou da validação do modelo através da análise comparativa do mapeamento das cicatrizes de possíveis escorregamentos com o mapa de previsão de áreas susceptíveis a escorregamentos, gerado para a Bacia do Córrego Independência.

Embora o Modelo SHALSTAB seja utilizado para prever áreas susceptíveis a ocorrência de escorregamentos translacionais rasos em áreas onde estejam bem definidos planos de transição com forte diminuição do processo de infiltração, como transição solo rocha, tornamos a destacar que este modelo também tem pontos falhos, não sendo tão eficaz para aplicações em áreas de solos espessos, áreas com baixa declividade, afloramentos de rochas, e áreas escarpadas (GUIMARÃES, 2000). Partindo destes princípios, descartou-se nesta análise os resultados obtidos nas porções de topos e de vales, por não serem considerados precisos. Uma prova disto é o fato do modelo gerado para a Bacia do Córrego Independência ter apresentado classificações de incondicionalmente instável tanto em condições de saturação como de insaturação em áreas de topo e de vale reconhecidamente planas ou quase planas (Figura 9). 
Susceptibilidade a Ocorrência de Escorregamentos na Bacia do Córrego Independência

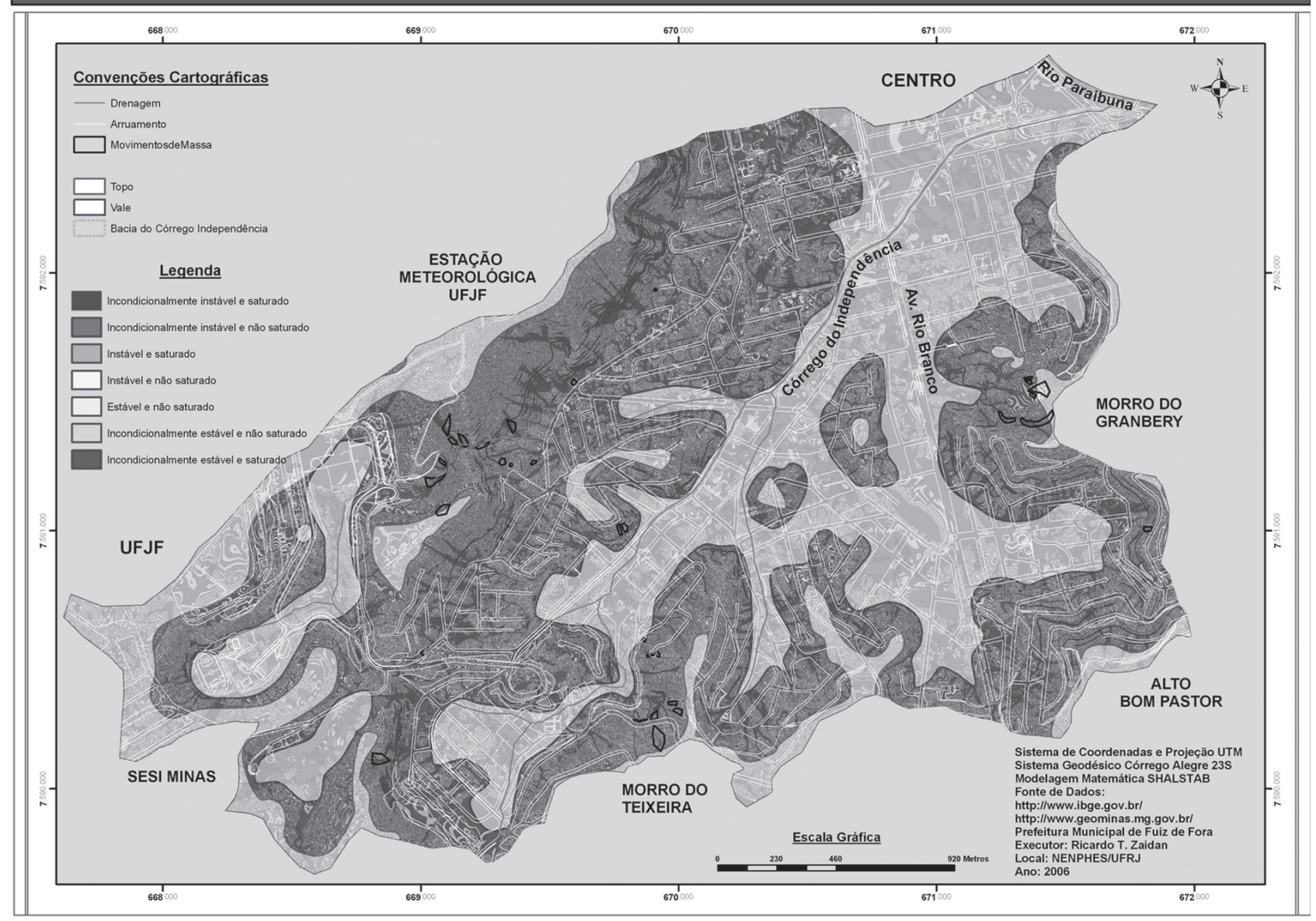

Figura 9 - Mapa representativo da susceptibilidade a escorregamentos na Bacia do Córrego Independência, ressaltando as cicatrizes de escorregamentos pretéritos. Nota-se que a classificação tem destaque apenas nas morfologias de encostas e para se facilitar as localizações foram traçadas as ruas em branco

\section{A Validação do Modelo de Previsão de Áreas Susceptíveis a Escorregamentos Aplicado na Bacia do Córrego Independência}

O conjunto de cicatrizes mapeado na área da Bacia do Córrego Independência pode ser dividido em quatro porções de acordo com aglomerações bem distintas: a porção leste, a sul, a sudoeste e a noroeste da bacia (podendo ser observadas nas Figuras 4 e 5).

A porção leste compõe um conjunto de cicatrizes nas encostas que circulam o Morro do Granbery. Caracterizamse por encostas de média altitude, de 700 a 850 metros, com geometria predominantemente côncava em planta e em perfil, com declividades acima de $30 \%$. Algumas das cicatrizes avançam pelo interflúvio de topo, mas isso se justifica por ser uma área, segundo o tipo de uso, pastagem loteamento não edificado, apresentando-se bem erodida e degradada, sem indícios de obras de reparação (Figura 10). Em relação à classificação de susceptibilidade, a maioria apresenta-se como instáveis e saturadas com traços de incondicionalmente instáveis com e sem saturação.

A porção sul compõe um conjunto de cicatrizes nas encostas do Morro do Teixeira. Caracterizam-se também por encostas de média altitude, de 700 a 850 metros, porém com geometria côncava em planta e em perfil apenas no local das cicatrizes. Os padrões de declividades também apresentam-se acima de 30\%, com predominância acima de $45 \%$. Corresponde a uma área, quanto ao uso, classificada como pastagem loteamento não edificado, porém com forte pressão de ocupação, sendo que em algumas vertentes já começam a surgir alguns loteamentos (Figura 11). Em relação à classificação de susceptibilidade aparecem apenas alguns pontos localizados como incondicionalmente instáveis com e sem saturação dentro da área das cicatrizes. Contudo, o local é reconhecidamente instável apresentando além das cicatrizes, registros pretéritos de alguns escorregamentos (Figura 11). 


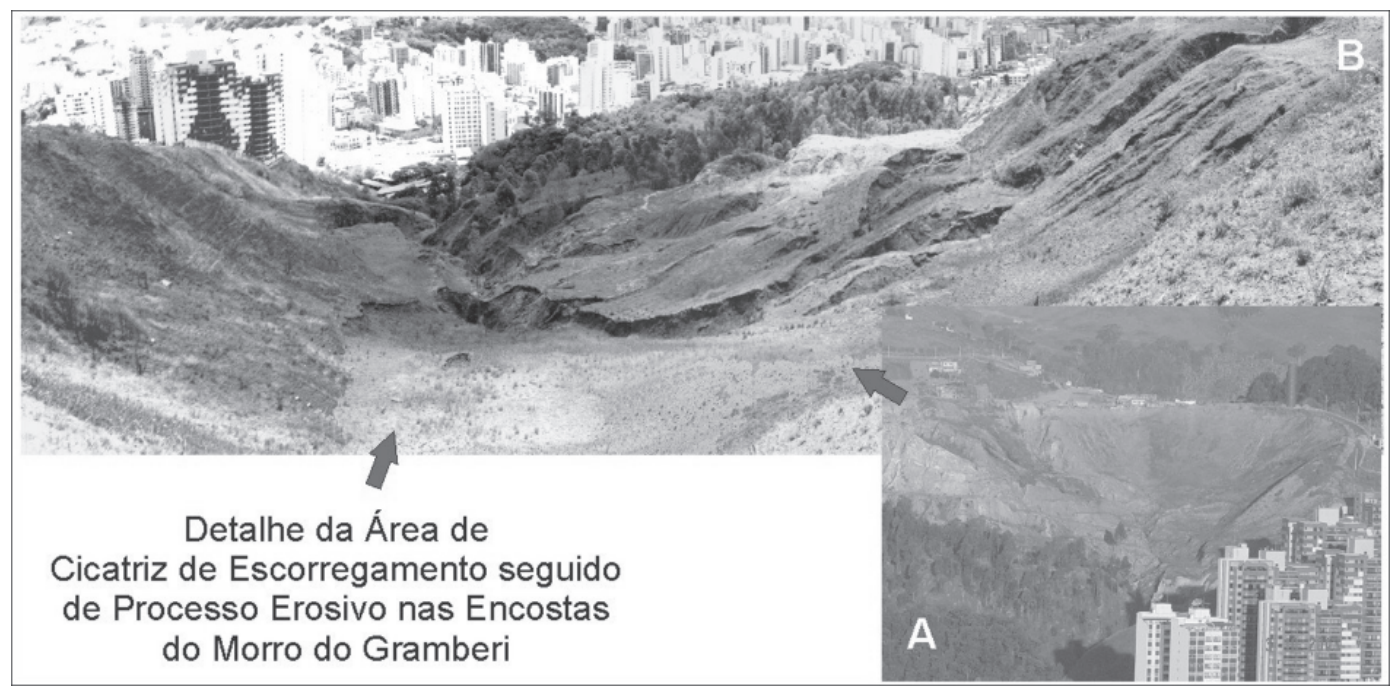

Figura 10 - Morro do Granbery (fotografia A) no centro da cidade, onde se encontram cicatrizes de possíveis escorregamentos seguidos de processo erosivo (fotografia $B$ ).

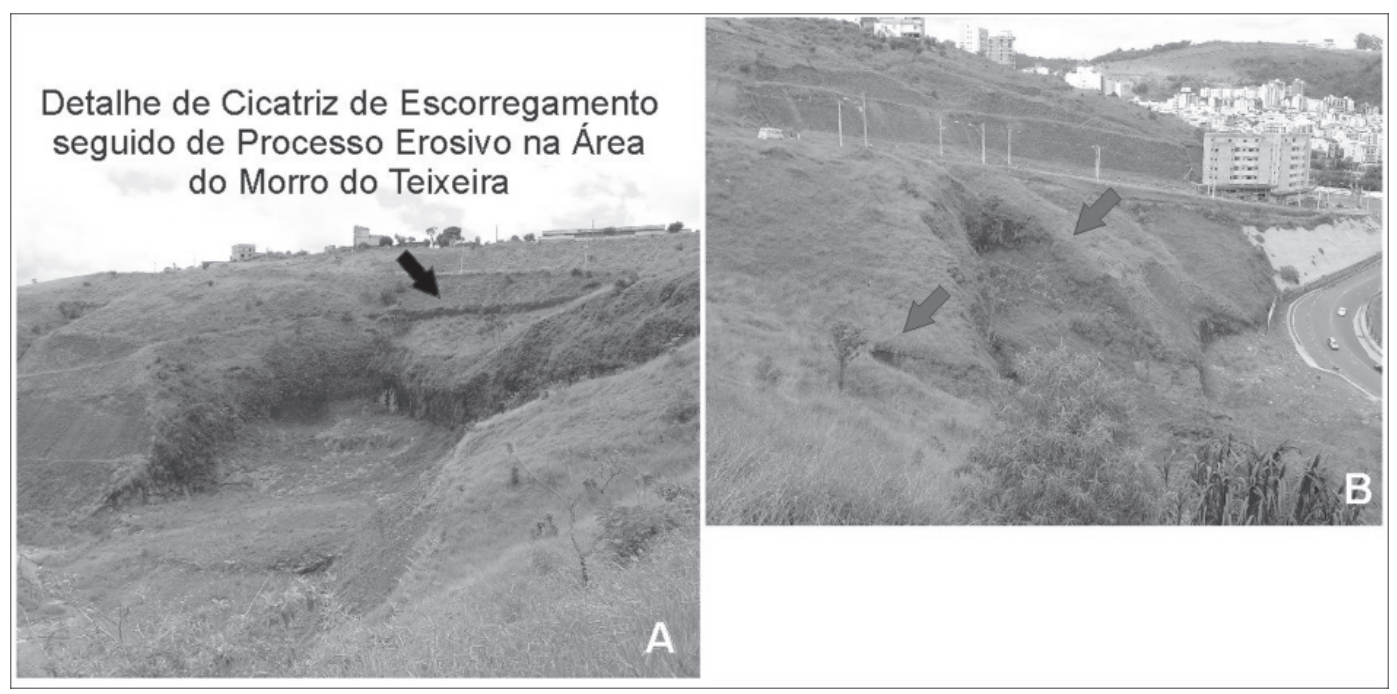

Figura 11 - Ambas fotografias nos mostram detalhes de cicatrizes no Morro do Teixeira, porção sul da bacia. A fotografia A mostra uma cicatriz acima de uma antiga praça de pedreira. A fotografia B nos mostra cicatrizes entre dois cortes de estradas.

A porção sudoeste possui apenas uma cicatriz na encosta que circula o bairro Cascatinha. Caracteriza-se por encostas acima de 800 metros de altitude com geometria predominantemente côncava em planta e em perfil, com declividades acima de $45 \%$. Encontra-se em uma área, segundo o tipo de uso, de pastagem loteamento não edificado, e em relação à classificação de susceptibilidade são na maioria incondicionalmente instáveis com e sem saturação (Figura 12). 


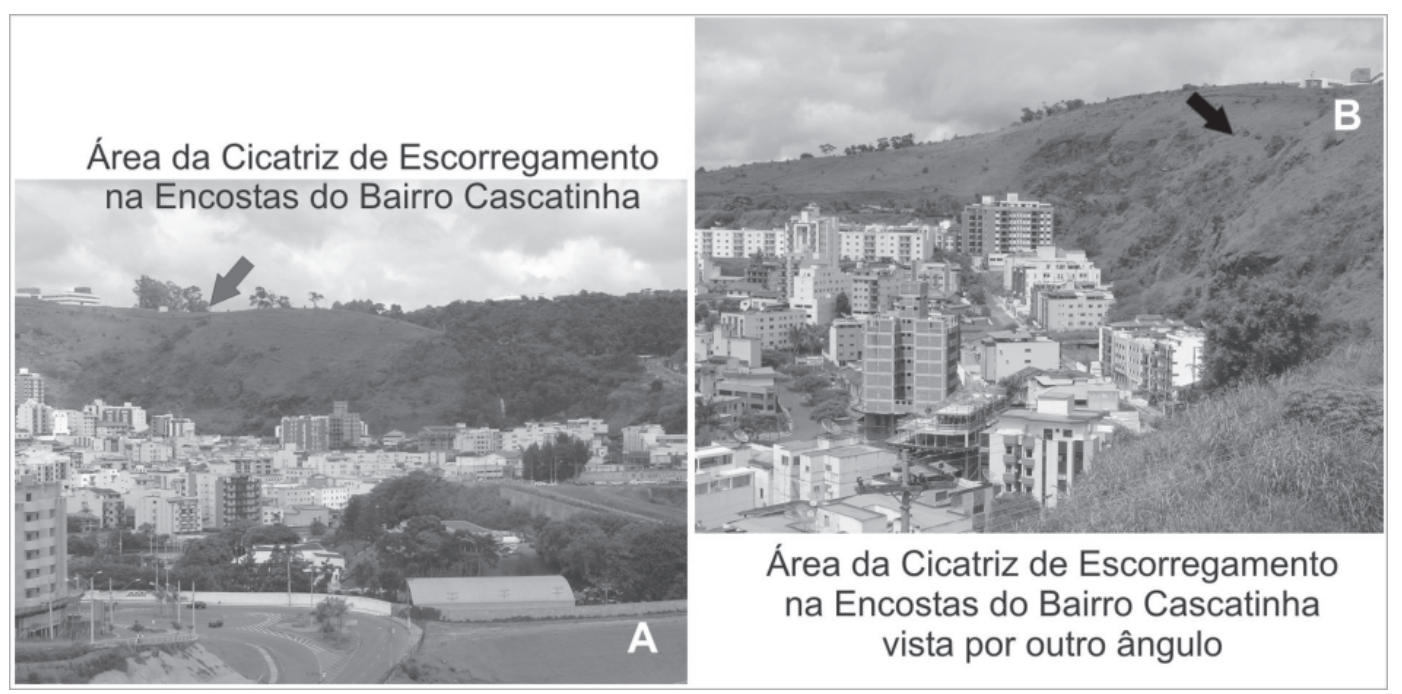

Figura 12 - A fotografia A e B são referentes ao bairro Cascatinha e representam a mesma encosta, porém vistas por ângulos diferentes. Encosta de geometria côncava em perfil e planta, de solos rasos com alguns afloramentos, ambiente típico de escorregamentos rasos.

A porção noroeste compõe um conjunto de cicatrizes nas encostas do bairro Dom Bosco, a jusante da Estação Meteorológica da UFJF. Caracteriza-se por encostas acima de 800 metros, com geometria predominantemente côncava em planta e em perfil no local das cicatrizes, com declividades acima de $30 \%$ predominando áreas com mais de $45 \%$. São características do tipo de uso, pastagem loteamento não edificado, apresentando algumas invasões e alto índice de queimadas durante o ano. Aparecem no local algumas obras de contenção e drenagem como reparação de longos processos erosivos após os escorregamentos (Figura 13). Em relação à classificação de susceptibilidade a maioria apresentou-se incondicionalmente instáveis com e sem saturação, apresentando dentre as demais áreas de cicatrizes, o maior índice de acerto de classificação instabilidade.

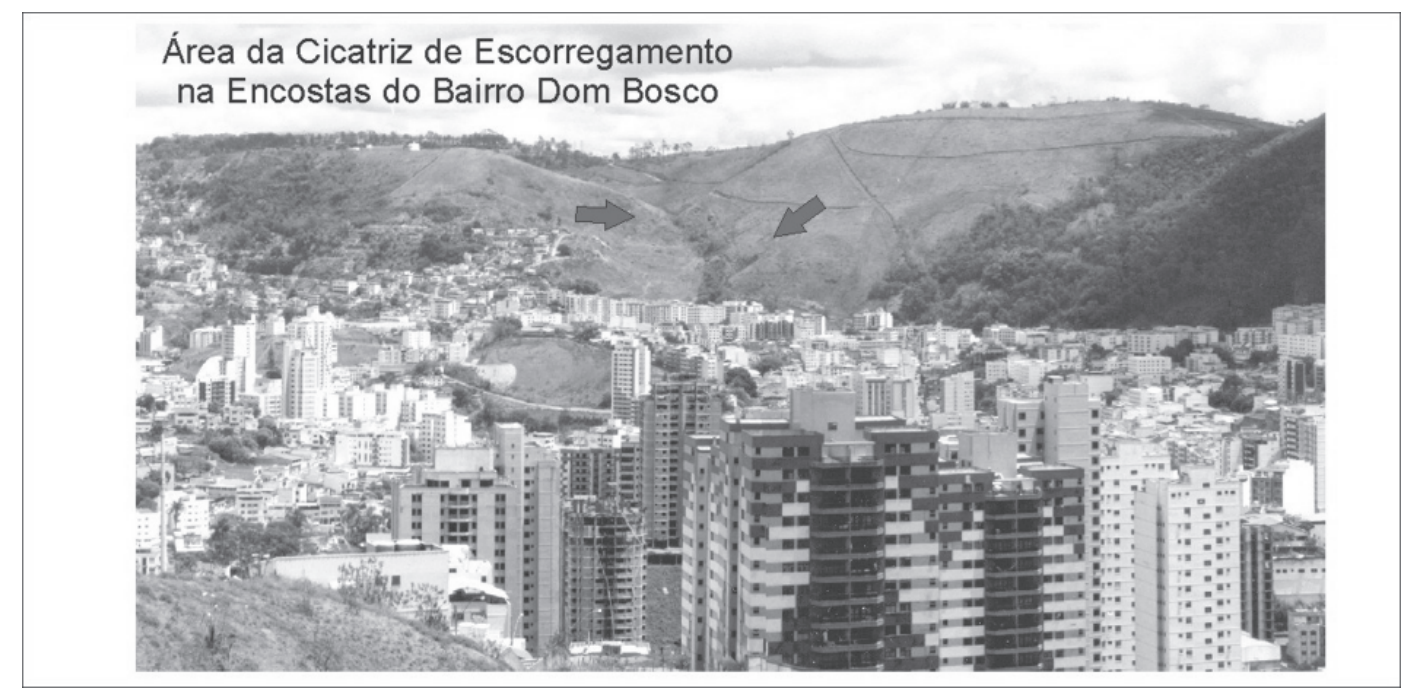

Figura 13 - Fotografia representativa de uma área de cicatrizes nas encostas a montante do bairro Dom Bosco à jusante da estação meteorológica da UFJF. 


\section{Análise do Zoneamento de Susceptibilidade a Escorregamentos Aplicado na Bacia do Córrego Independência}

O zoneamento de susceptibilidade a escorregamentos nas encostas da Bacia do Córrego Independência foi criado a partir da análise das classes de susceptibilidade apresentadas pelo modelo SHALSTAB. Para simplificar o entendimento, criou-se três classes de susceptibilidade para a área das encostas da bacia, a partir do agrupamento das classes geradas pelo SHALSTAB, como definido no capítulo anterior. As classes são as seguintes: áreas estáveis, áreas de média instabilidade e áreas instáveis (Figura 14).

\section{Zoneamento de Susceptibilidade a Escorregamentos na Bacia do Córrego Independência}

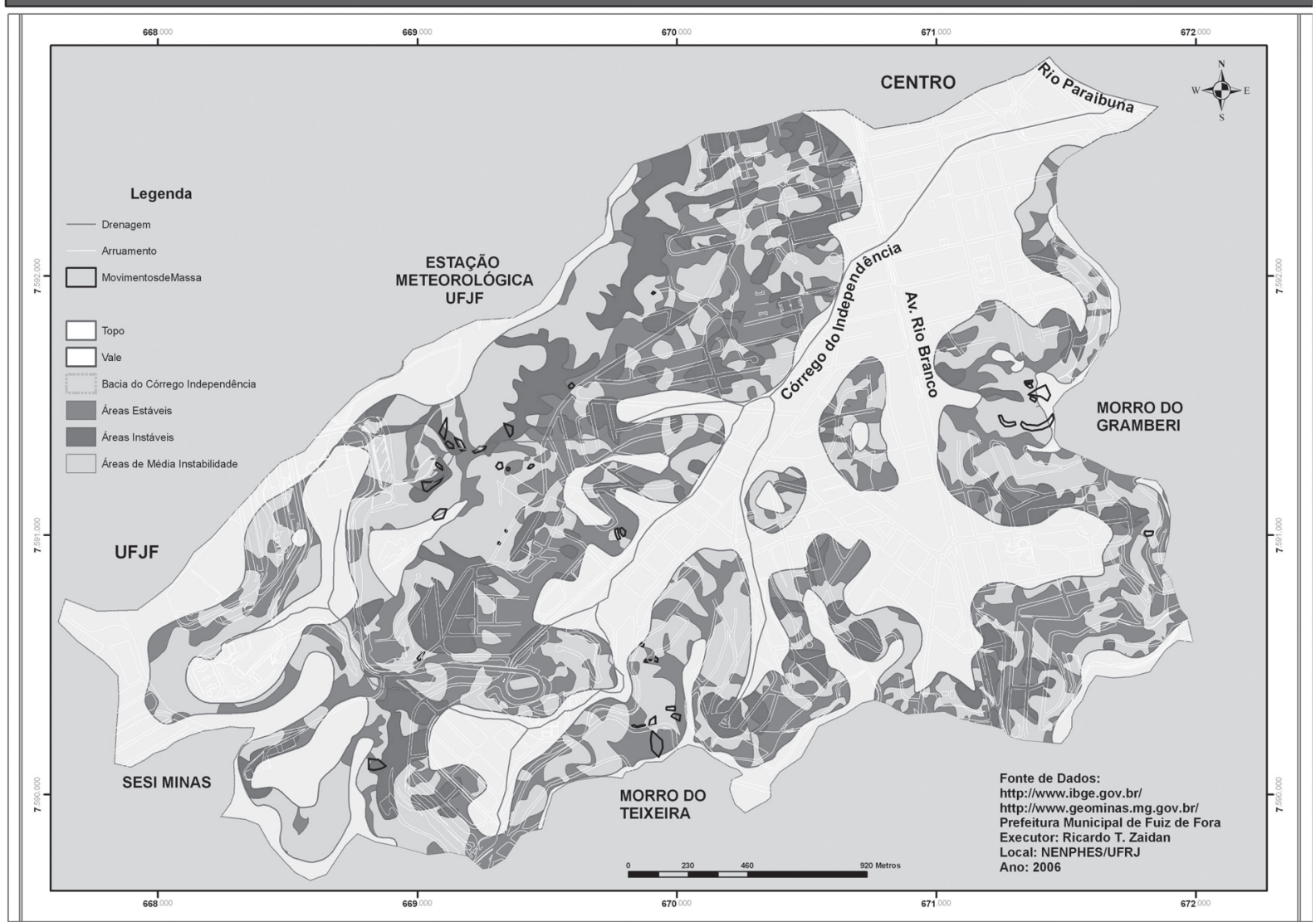

Figura 14 - Representação do Mapa de Susceptibilidade a Escorregamentos nas Encostas da Bacia do Córrego Independência.

A classe de áreas estáveis caracteriza-se por compor cerca de $34 \%$ do total das encostas da bacia (Gráfico 2). Estão bem distribuídas pelas encostas, porém aparecem com maior frequência em alguns locais como é o caso das porções leste e nordeste, nas proximidades do Morro do Granbery. Outro local que é mais frequente é na porção sul nas proximidades do Morro do Teixeira, juntamente com a porção sudoeste, nas área da UFJF, onde predominam áreas mais estáveis da bacia. Nas demais áreas do mapa, como a encosta norte-noroeste, que corresponde às proximidades da estação meteorológica e nas encostas da porção sudoeste, nas proximidades do SESI Minas, área que corresponde a parte do bairro Cascatinha, as áreas estáveis aparecem mais entremeadas a áreas instáveis, sendo mais frequentes nos terços inferiores das encostas.
A classe de áreas de média instabilidade apresentou uma distribuição bem regular em quase toda a área das encostas da Bacia do Córrego Independência, caracterizando-se por cerca de $46,7 \%$ de toda a área da encosta da bacia (Gráfico 2). Possui menor regularidade no terço inferior da grande encosta que vai da porção norte a sudoeste da bacia, correspondendo às proximidades da estação meteorológica da UFJF, onde se encontra o bairro Dom Bosco. Apresenta-se bem frequente no terço superior desta mesma encosta e de uma maneira geral, no restante de toda a área, com exceção das encostas próximas do SESI Minas, onde se encontra parte dos bairros Cascatinha e Teixeira, revelando através de sua distribuição um padrão de ocorrência sempre próximo das áreas classificadas como estáveis. 
Gráfico 2 - Percentual de ocorrência das classes do Zoneamento de Susceptibilidade a Escorregamentos nas Encostas da Bacia do Córrego Independência.

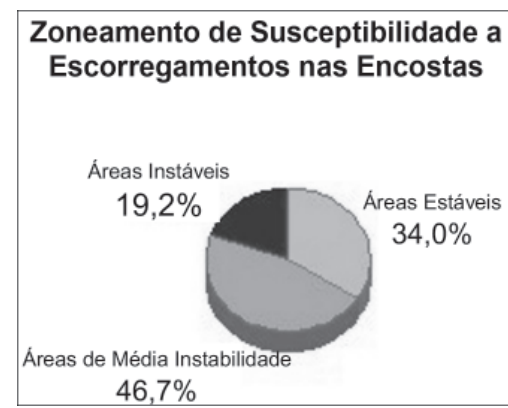

A classe de áreas instáveis apresentou-se em menor quantidade, caracterizando 19,2\% das encostas da Bacia do Córrego Independência (Gráfico 2). Através da análise do mapa com o zoneamento de susceptibilidade nas encostas da bacia fica bem claro sua área de destaque através da encosta que vai do norte, passando pelo oeste e chegando ao sudoeste do mapa, passando pela estação meteorológica da UFJF até as proximidades do SESI Minas, com exceção da região da UFJF que não apresenta quantidade significativa de áreas com tal classificação. No restante do mapa elas aparecem com menor frequência, pontualmente nas encostas do morro do Teixeira, passando pela porção sudeste do mapa onde se evidenciam um pouco mais, até a porção nordeste, nas proximidades do Morro do Granbery e Rio Paraibuna, onde também aparecem com menor frequência.

\section{Conclusão}

Quanto A caracterização de Áreas Críticas no Município de Juiz de Fora

A configuração de áreas críticas e degradadas caracterizando situações de risco atual tem se elevado com o aumento populacional, principalmente através das ocupações nas encostas mais íngremes das bacias de drenagem periféricas à calha do rio principal onde se encontra o centro comercial da cidade. Conclui-se que este fenômeno se dá devido à necessidade criada pela população de ocupar áreas periféricas e próximas a este centro comercial onde existe a maior parte dos empregos. Não que o município não possua áreas adequadas à expansão urbana, é que estas áreas, além de serem distantes, não se encontram servidas de infra-estrutura adequada com os mesmos padrões do centro da cidade. Devido a isso, conclui-se o porquê das ocupações nas áreas inadequadas, próximas do centro de trabalho local, onde há emprego.

\section{Quanto ao uso e ocupaçãona Bacia do Córrego Independência}

A Bacia do Córrego Independência caracteriza-se como uma bacia essencialmente urbana, periférica, porém próxima ao centro comercial do município, o que em parte explica o adensamento populacional, a ocupação das áreas menos adequadas do ponto de vista morfológico do relevo, exercendo uma pressão constante nas suas porções que ainda não foram ocupadas.

A classe Áreas de Uso e Ocupação Urbana caracteriza-se essencialmente residencial e comercial sem uso industrial e é a responsável pela forte pressão de ocupação e começa a avançar sobre as demais classes de uso. Constatou-se que as áreas mais degradas correspondem às "Pastagens ou Loteamento não Edificados", pois, registram a ocorrência de queimadas constantes, cortes de talude e ocupações muitas vezes por invasões, o que não ocorre seguido de infra-estrutura necessária, gerando maiores impactos, como a retirada da cobertura vegetal, cortes de taludes, disposição inadequada deste material retirado da encosta, disposição inadequada de resíduos sólidos nos seus arredores, criação de novos efluentes de esgoto a céu aberto, dentre outros inúmeros exemplos que ainda poderiam ser mencionados. As Matas Urbanas correspondem às áreas de mais difícil acesso ou de maior dificuldade de ocupação e também às antigas propriedades, como instituições religiosas e públicas, como bordas de cemitérios, hospitais e colégios. Constata-se também, que tem sofrido grande pressão de ocupação, não só de classes sociais desfavorecidas como das mais favorecidas economicamente. Porém, estas áreas que tem sofrido este tipo de ação constituem em sua maioria áreas públicas com elevado gradiente e destinadas à preservação, devido sua condição morfológica da encosta onde se encontra, podendo, independentemente da classe social que a venha ocupar, contribuir para o aparecimento de novas áreas críticas, desencadeando processos que possivelmente ocasionarão danos às áreas ocupadas a jusante. Quanto a este último fato, sugere-se estudos futuros relacionados à área de deposição de possíveis escorregamentos e a análise conjunta do mapeamento de uso e ocupação para a verificação de possíveis danos à população relativos ao material desagregado e sua área de deposição imediata.

\section{Quanto a Previsão de Áreas Susceptíveis a Escorregamentos na Bacia do Córrego Independência}

Quanto à previsão de áreas susceptíveis a escorregamentos na Bacia do Córrego Independência, o mapeamento de cicatrizes mostrou que as mesmas quase que não aparecem, em sua totalidade, em áreas de uso e ocupação urbana. Isto confirma a grande dinâmica ocupacional da bacia em questão onde o acelerado processo de ocupação 
nos últimos anos contribuiu para a alteração rápida da paisagem através da possível ocupação e alteração das áreas de antigos escorregamentos, camuflando a existência de registros pretéritos desses processos. Esta dinâmica também pode ser considerada como a explicação de outro problema, que foi a dificuldade de se classificar os tipos de movimentos de massa que geraram a maior parte das cicatrizes mapeadas, ainda mais que a maioria apresentou-se em estágio erosivo avançado e também já modificada por possíveis obras de remoção do entulho e reparo do dano provocado. Apesar disso e da dificuldade de se analisar o mapa de susceptibilidade de forma analógica, devido a não geração de manchas homogêneas, o modelo de susceptibilidade gerado para a bacia, apresentou resultados satisfatórios quanto ao seu processo de validação constatando-se que na área de cada cicatriz, apareceram células instáveis ou incondicionalmente instáveis, podendo-se afirmar que houve $100 \%$ de acerto, em relação à ocorrência de pelo menos uma célula instável ou incondicionalmente instável dentro da área de cada cicatriz. Aponta-se que a área que apresentou maior acerto foi a da encosta a jusante da estação meteorológica.

Sugere-se que quanto ao método de validação, seja feito um inventário da classificação das células de susceptibilidade dentro da área de cada cicatriz para se verificar a proporção de instabilidade dentro de cada cicatriz. Além do mais, seria interessante testar modelos de generalização cartográfica nos mapas gerados pelo SHALSTAB, para se tentar eliminar impurezas ou ruídos, o que poderia melhorar os resultados para a futura análise analógica ou digital dos mapas.

\section{Quanto ao Zoneamento de Susceptibilidade a Escorregamentos Aplicado na Bacia do Córrego Independência}

Conclui-se que as áreas de encosta da bacia que possuem menor instabilidade correspondem às porções leste, sul e oeste, respectivamente o campus da UFJF, grande parte do Morro do Teixeira e boa parte do Morro do Granbery. Já as áreas de maior instabilidade destacam-se claramente através da encosta que vai da porção norte, passando pela oeste e chegando a sudoeste do mapa, passando a jusante da estação meteorológica da UFJF até as proximidades do SESI Minas alcançando uma parte das encostas do Morro do Teixeira, com exceção, é claro, da região da UFJF. Esta grande encosta corresponde ao grande lineamento constituído por um falhamento de direção nordeste-sudoeste mencionado em descrições do capítulo anterior.

Sugestão - análise conjunta das situações de susceptibilidade com a de risco, para a detecção das áreas susceptíveis a montante das áreas urbanas, pois os escorregamentos geram áreas de deposição a jusante, e isto não está previsto no zoneamento de risco atual. Tal estudo pode ser interessante para a criação de planos preventivos.

Como forma de finalizar, sugerimos alguns estudos futuros que possam servir de continuidade a este trabalho. Achamos de grande importância uma análise da legislação de uso e ocupação do solo com o uso e ocupação do solo atual para a verificação de ilegalidades. Outro aspecto interessante seria a análise da legislação de uso e ocupação do solo com o zoneamento de susceptibilidade a escorregamentos para se verificar a eficácia da legislação e até mesmo a criação e proposição de futuras adequações da legislação para se inibir a ocupação dessas áreas críticas. Para finalizar, achamos também de grande importância a realização da análise da legislação de uso e ocupação do solo com um zoneamento de risco de movimentos de massa da área da Bacia do Córrego Independência para verificar se a legislação está sendo infringida ou se não contemplou as áreas de restrição de uso, para que sejam criadas proposições como contribuição para futuras adequações da legislação de parcelamento, uso e ocupação do solo no perímetro urbano do Município de Juiz de Fora.

\section{Referências Bibliográficas}

ABRAHAMS, A. D., Ed. Hillslope Processes. The Binghampton Symposium in Geomorphology. v.16, 1986. 416 p. (The Binghampton Symposium in Geomorphology)

AHNERT, F. Introduction to Geomorphology. London: Arnold, 1998. 352 p.

AMARAL, C. Landslides Disasters Management in Rio de Janeiro. 2nd Pan-American Symposium on Landslides (II PSL) / $2^{\text {a }}$ Conferência Brasileira Sobre Estabilidade de Encostas ( $2^{\text {a }}$ COBRAE), ABMS, ABGE e ISSMGE. Rio de Janeiro, Brazil: 1997. p.209-212.

AMARAL, C. e FEIJÓ, R. L. Aspectos Ambientais dos Escorregamentos em Áreas Urbanas. In: VITTE, A. C. e GUERRA, A. J. T. (Ed.). Reflexões sobre a Geografia Física no Brasil. Rio de Janeiro: Bertrand Brasil, 2004. p.193-224.

AMARAL, C. e FURTADO, A. Large-scale quantitative landslide risk mapping at Favela da Formiga, Rio de Janeiro. In: LACERDA, W. A.; EHRLICH, M.; FONTOURA, S. A. B. e SAYÃO, A. S. F. (Ed.). Landslides: Evaluation and stabilization. London: Taylor \& Francis Group, 2004. p.293-296.

AMARAL, C. P. D. Escorregamentos no Rio de Janeiro: Inventário, Condicionantes e Redução do Risco. Departamento de Engenharia Civil, Pontifícia Universidade Católica do Rio de Janeiro, Rio de Janeiro, 1996. 262p. (Doutorado). 
ARAUJO, G. H. D. S.; ALMEIDA, J. R. D. e GUERRA, A. J. T. Gestão Ambiental de Áreas Degradadas. Rio de Janeiro: Bertrand Brasil, 2005. 320 p.

AUGUSTO FILHO, O. e VIRGILI, J. C. Estabilidade de Taludes. In: OLIVEIRA, A. M. D. S. e BRITO, S. N. A. D. (Ed.). Geologia de Engenharia. São Paulo: ABGE, 2004. p.243-269.

AUGUSTO FILHO, O. e WOLLE, C. M. Cartas de Risco de Escorregamentos: Uma Proposta Metodológica e sua Aplicação no Município de IlhaBela, SP. $\underline{\text { Solos }}$ e Rochas. 19: 45-62 p. 1996.

BEVEN, K. J. e KIRKBY, M. J. A physically based, variable contributing area model of basin hydrology. Bulletin of Hydrological Sciences, v.24, n.1, p.4369, 1979.

BRUNSDEN, D. e PRIOR, D. B., Eds. Slope Instability. Chichester: John Wiley, 1984. 602 p.

CARSON, M. A. e KIRKBY, M. J. Hillslope form and process. Cambridge University Press, 1972. 475 p.

CASADEI, M.; DIETRICH, W. E. e MILLER, N. L. Testing a Model for Predicting the Timing and Location of Shallow Landslide Initiation in soil-mantled landscapes. Earfh Surface Processes and Landforms, v.28, p.925-950, 2003.

CESAMA/PMJF. Levantamento Aerofotográfico do Perímetro Urbano de Juiz de Fora. $1^{\mathrm{a}} \mathrm{ed}$. Juiz de Fora: Foton Aerolevantamentos, 2000. (Resolução $40 \mathrm{~cm})$

CHORLEY, R. e BECKINSALE, R. P. G. K. Gilbert's Geomorphology. In: YOCHELSON, E. L. (Ed.). The Scientific Ideas of G. K. Gilbert. Boulder, CO: Geological Society of America, v.Special Paper 183, 1984. p.129-142.

CHORLEY, R. J. e HAGGETT, P., Eds. Models in Geography. London: Methuen, 1967. p.

CHRISTOFOLETTI, A. Geomorfologia. $2^{\mathrm{a} e d . ~ S a ̃ o ~ P a u l o: ~}$ Edgard Blücher, 2002. 188 p.

CHRISTOFOLLETI, A. Modelagem de Sistemas Ambientais. São Paulo: Edgard Blucher, 1999. 236 p.

CLAESSENS, L.; HEUVELINK, G. B. M.; SCHOORL, J. M. e VELDKAMP, A. DEM resolution effects on shallow landslide hazard and soil redistribution modelling. Earfh Surface Processes and Landforms, v.30, p.461-477, 2005.

CLARK, M. J. e SMALL, J. J. Slopes and Weathering. Cambridge: Cambridge University Press, 1982. 112 p. (Cambridge Topics in Geography)
CROZIER, M. J. Landslides; Causes, Consequences, and Environment. London: Croom Helm, 1986. 252 p.

CRUDEN, D. M. Estimating the risks from landslides using historical data. In: CRUDEN, D. M. e FELL, R. (Ed.). Landslide Risk Assessment. Rotterdam: Balkema, 1997. p.177-184.

DIETRICH, W. E. e MONTGOMERY, D. R. SHALSTAB: A Digital Terrain Model for Mapping Shallow Landslide Potential. National Council for Air and Stream Improvement. February 1, 1998, p.26. 1998

DIETRICH, W. E.; WILSON, C. T.; MONTGOMERY, D. R.; MCKEAN, J. e BAUER, R. Erosion thresholds and land surface morphology. Geology, v.20, p.675-679, 1992.

DIETRICH, W. E., WILSON, C. J., MONTGOMERY, D. R., AND MCKEAN, J. Analysis of Erosion Thresholds, Channel Networks, and Landscape Morphology using a Digital terrain Model. The Journal of Geology, v.101, n.2, p.259-278, 1993.

EMBRAFOTO. Restituição Aerofotogramétrica do Município de Juiz de Fora. Juiz de Fora: PMJF/ IPPLAN, 1983. (1:2000)

FERNANDES, N. F. Modelagem Matemática em Geomorfologia: Potencialidades e Limitações. Sociedade e Natureza, v.15, p.222-227, 1996.

FERNANDES, N. F. e AMARAL, C. P. Movimentos de massa: uma abordagem geológicogeomorfológica. In: GUERRA, A. J. T. e CUNHA, S. B. (Ed.). Geomorfologia e meio ambiente. Rio de Janeiro 1996. p.123-194.

FERNANDES, N. F; GUIMARÃES, R. F.; GOMES, F. A. T.; VIEIRA, B. C.; MONTGOMETY, D. R. e GREENBERG, H. Condicionantes Geomorfológicos dos Deslizamentos nas Encostas: avaliação de metodologias e aplicação de modelo de previsão de áreas susceptíveis. Revista Brasileira de Geomorfologia, v.2, n.1, p.51-71, 2001.

FERNANDES, N. F.; GUIMARAES, R. F.; GOMES, R. A. T.; VIEIRA, B. C.; MONTGOMERY, D. R. e GREENBERG, H. Topographic controls of landslides in Rio de Janeiro: field evidence and modeling. CATENA, v.55, n.2, p.163-181, 2004. http://www.sciencedirect.com/science/article/ B 6 V C G - 4 9 C T 5 T M - 2/2/ 0af136c4f538365e2f60a10b95d9971f

FRANCIS, S. C. Slope development through the threshold slope concept. In: ANDERSON, M. G. e RICHARDS, K. S. (Ed.). Slope Stability. John Wiley \& Sons, 1987. p.601-624. 
FREIRE, E. S. M. Movimentos Coletivos de Solos e Rochas e sua Moderna Sistemática. Construção - Rio de Janeiro, v.8, p.10-18, 1965.

GARCIA, R. A. C. e ZÊZERE, J. L. Abadia Basin - Torres Vedras, Portugal - a case study of landslide susceptibility assessment and validation. In: LACERDA, W. A.; EHRLICH, M.; FONTOURA, S. A. B. e SAYÃO, A. S. F. (Ed.). Landslides: Evaluation and stabilization. London: Taylor \& Francis Group, 2004. p.137-142.

GOMES, R. A. T. Condicionantes Geomorfológicos e o Efeito da Escala Cartográfica na Previsão de Áreas Críticas a Deslizamentos. Departamento de Geografia, UFRJ, Rio de Janeiro, 2002. 109p. (Mestrado).

GOMES, R. A. T.; GUIMARÃES, R. F.; CARVALHOJÚNIOR, O. A. D. e FERNANDES, N. F. Análise da influência da escala cartográfica no resultado de um modelo de previsão de áreas críticas a deslizamentos. Ciência e Natura - UFSM, p.269286, 2004.

GOMES, R. A. T.; GUIMARÃES, R. F.; CARVALHO JR., O. A. e FERNANDES, N. F. Análise de um modelo de previsão de deslizamentos (SHALSTAB) em diferentes escalas cartográficas. Revista Solos e Rochas - ABGE/ABMS, v.28, n.1, Janeiro-Abril, p.85-97, 2005.

GUIDICINI, G. e NIEBLE, C. M. Estabilidade de taludes naturais e de escavação. $2^{\mathrm{a}}$ ed. São Paulo: Edgard Blücher, 1984.

GUIMARÃES, R. F. A modelagem matemática na avaliação de áreas de risco a deslizamentos: o exemplo das bacias dos rios Quitite e Papagaio (RJ). Depto de Geologia, UFRJ, Rio de Janeiro, 2000 (Doutorado).

GUIMARÃES, R. F.; MONTGOMERY, D. R.; GREENBERG, H. M.; FERNANDES, N. F.; GOMES, R. A. T. e JÚNIOR, O. A. D. C. Parameterization of soil properties for a model of topographic controls on shallow landsliding: application to Rio de Janeiro. Engineering Geology, v.2137, p.1-10, 2002.

GUZZETTI, F.; CARRARA, A.; CARDINALI, M. e REICHENBACH, P. Landslide hazard evaluation: a review of current techniques and their application in a multi-scale study, Central Italy. Geomorphology, v.31, n.1-4, p.181-216, 1999. http://www.sciencedirect.com/science/article/
B 6 V $93-3$ Y S Y 1 B F - T / 2/ 1696b4d9c17d6ae12bc7a0017d654a02

HUTCHINSON, J. N. General report: Morphological and geotechnical parameters of landslides in relation to geology and hydrogeology. Proceedings of the 5th International Symposium on Landslides. Lausanne: A. A. Balkema, 1988. p.3-35.

IBGE. Folha Eubank da Câmera. SF-23-X-C-VI-2. $1^{\text {aed. }}$ Brasília: Secretaria de Planejamento da República - Diretoria de Geodésia e Cartografia, Superintendência de Cartografia, 1976a. (1:50.000) (http://www.ibge.gov.br/)

Folha Juiz de Fora. SF-23-X-D-IV-1. 1ªed. Brasília: Secretaria de Planejamento da República Diretoria de Geodésia e Cartografia, Superintendência de Cartografia, 1976b. (1:50.000) (http://www.ibge.gov.br/)

Folha Mar de Espanha. SF-23-X-D-IV-4. Brasília: Secretaria de Planejamento da República Diretoria de Geodésia e Cartografia, Superintendência de Cartografia, 1976c. (1:50.000) (http://www.ibge.gov.br/)

Folha Matias Barbosa. SF-23+X-D-IV-3. $1^{\text {a ed. }}$ Brasília: Secretaria de Planejamento da República - Diretoria de Geodésia e Cartografia, Superintendência de Cartografia, 1976d. (1:50.000) (http://www.ibge.gov.br/)

Folha Santa Bárbara do Monte Verde. SF-23-X-CVI-4. $1^{\mathrm{a}}$ ed. Brasília: Secretaria de Planejamento da República - Diretoria de Geodésia e Cartografia, Superintendência de Cartografia, 1976e. (1:50.000) (http://www.ibge.gov.br/)

Folha São João Nepomuceno. SF-23-X-D-IV-2. $1^{\text {aed. }}$ Brasília: Secretaria de Planejamento da República - Diretoria de Geodésia e Cartografia, Superintendência de Cartografia, $1976 f$. (1:50.000) (http://www.ibge.gov.br/)

IPT. Ocupação de Encostas. São Paulo: IPT, v.1831. 1991. $216 \mathrm{p}$.

KELLER, E. A. Environmental Geology. 7th ${ }^{\mathrm{a}}$ ed. Upper Saddle River, NJ: Prentice - Hall, 1996. 560 p.

KRUMBEIN, W. C. e GRAYBILL, F. A. An Introduction to Statistical Models in Geology. New York: McGraw Hill, 1965.

LACERDA, W. A. Stability of Natural Slopes Along the Tropical Coast of Brazil. In: ALMEIDA, M. (Ed.). Proceding of the Internacional Symposium on 
Recent Developments in Soil and Pavement Mechanics. Brookfield, 1997. p.17-39.

LEE, S.; CHOI, J. e RYU, J.-H. Probabilistic landslide hazard mapping using GIS and remote sensing data at Boun, Korea. In: LACERDA, W. A.; EHRLICH, M.; FONTOURA, S. A. B. e SAYÃO, A. S. F. (Ed.). Landslides: Evaluation and stabilization. London: Taylor \& Francis Group, 2004. p.85-90.

MONTGOMERY, D. R. Road Surface Drainage, Channel Initiation, and Slope Stability. Water Resources Research, v.30, n.6, p.1925-1932, 1994.

MONTGOMERY, D. R. e DIETRICH, W. E. A physically based model for the topographic control on shallow landsliding. Water Resources Research, v.30, n.4, p.1153-1171, 1994.

MORGAN, R. P. C. Soil Erosion and Conservation. $2^{\mathrm{a}} \mathrm{ed}$. London: Longman, 1995.

MORGENSTERN, N. R. e SANGREY, D. A. Methods of Stability Analysis. In: SCHUSTER, R. L. e KRIZEK, R. J. (Ed.). Landslides: Analysis and Controls. Washington D.C.: NAS-NRC, 1978. p.155-171.

O'LOUGHLIN, E. M. Prediction of Surface Saturation Zones in Natural Catchments by Topographic Analysis. Water Resources Research. 22: 794-804 p. 1986.

PARSONS, A. J. Hillslope Form. London: Routledge, 1988. $212 \mathrm{p}$.

PMJF. Plano Diretor de Desenvolvimento Urbano de Juiz de Fora. Juiz de Fora: PMJF, v.2. 1999. 285 p.

. Plano Diretor de Desenvolvimento Urbano de Juiz de Fora. Juiz de Fora: Prefeitura Municipal de Juiz de Fora - FUNALFA Edições, 2004. 394 p.

PRESS, F. e SIEVER, R. Understanding Earth. $3^{\text {a ed. New }}$ York: W. H. Freeman and Company, 2000. 573 p.

RABACO, L. M. L. Avaliação de Modelos de Susceptibilidade a Movimentos Gravitacionais de Massa numa Faixa de Dutos. Engenharia de Computação / Geomática, FEN/UERJ, Rio de Janeiro, 2005. 162p. (Mestrado).

RAFAELLI, S. G.; MONTGOMERY, D. R. e GREENBERG, H. M. A comparison of thematic mapping of erosional intensity to GIS-driven process models in an Andean drainage basin. Jornal of Hydrology, v.244, p.33-42, 2001.

RAMOS, V. M.; GUIMARÃES, R. F.; REDIVO, A. L.; GOMES, R. A. T.; FERNANDES, N. F. e CARVALHO FILHO, O. A. Aplicação do modelo shalstab, em ambiente arcview para o mapeamento de áreas susceptíveis a escorregamentos rasos na região do Quadrilátero Ferrífero - MG. Espaço e Geografia, v.5, n.1, p.49-57, 2002.

REDIVO, A. L.; RAMOS, V. M.; GUIMARÃES, R. F.; JÚNIOR, O. A. D. C. e GOMES, R. A. T. Determinação de áreas susceptíveis a escorregamentos na $\mathrm{Br} 256$ no município de Ouro Preto - MG. Ciência e Natura - UFSM, p.31-46, 2004.

SASSA, K. Geotechnical Classification of Landslides. Landslide News, v.3, p.21-24, 1989.

SCHEIDEGGER, A. E. Physical Aspects of Natural Catastrophes. Amsterdam: Elsevier, 1975. 289 p.

SELBY, M. J. Hillslope Materials and Processes. $2^{\mathrm{a}} \mathrm{ed}$. New York: Oxford University Press, 1993. 451 p.

SHARPE, C. F. S. Landslides and related phenomena: A study of mass-movements of soil and rock. New york: Columbia University Press, 1938. 137 p.

SMALL, R. J. The study of landforms. $2^{\mathrm{a}}$ ed. New York: Cambridge University Press, 1978. 502 p.

SOUZA, C. B. D.; NUNES, A. L. L. S. e LACERDA, W. A. Mapeamento de Áreas de Risco para Ocupação Urbana através de SIG. Conferência brasileira sobre estabilidade de encostas. Rio de Janeiro: III COBRAE, 2001. p.261-269.

TRICART, J. Précis de Géomorphologie. Paris: SEDES, v.2. 1977. $345 \mathrm{p}$.

VARNES, D. J. Slope movements types and processes. In: SCHUSTER, R. L. e KRIZEK, R. J. (Ed.). Landslides. Analysis and Control. Washington: National Academy of Science, v.Transportation Research Board Special Report, 1978. p.11-33.

VIEIRA, B. C. e FERNANDES, N. F. Landslides in Rio de Janeiro: The Role Played by Variations in Soil Hidraulic Condutivity. Hydrological Processes, v.18, p.791-805, 2004.

WOlle, C. M. e CARVALHO, C. S. Deslizamentos em encostas na Serra do Mar - Brasil. Solos e Rochas, v.12, p.27-36, 1989.

XAVIER-DA-SILVA, J. Geoprocessamento para Análise Ambiental. Rio de Janeiro: sn, 2001. 228 p. 